\title{
INTEGRAÇÃO DE TECNOLOGIA NA EDUCAÇÃO: PROPOSTA DE MODELO PARA CAPACITAÇÃO DOCENTE INSPIRADA NO TPACK
}

\author{
JUAREZ BENTO DA SILVA ${ }^{1}$ \\ ORCID: https://orcid.org/0000-0002-5604-0576 \\ SIMONE MEISTER SOMMER BILESSIMO ${ }^{2}$ \\ ORCID: https://orcid.org/0000-0002-3326-8703 \\ LETICIA ROCHA MACHADO 3 \\ ORCID: https://orcid.org/0000-0003-4102-2225
}

\begin{abstract}
RESUMO: A integração tecnológica geralmente é entendida como a incorporação de tecnologia nas salas de aula. No entanto, um dos pontos que merece mais atenção é a forma como essa inclusão tem sido feita no processo de ensino, nas experiências de aprendizagem e no currículo. Assim, é possível afirmar que a integração das Tecnologias de Informação e Comunicação (TIC) na sala de aula envolve competências específicas dos docentes em relação ao uso pedagógico das tecnologias. Os professores devem adquirir e desenvolver continuamente conhecimentos, habilidades e atitudes pertinentes à área no intuito de incluir os recursos tecnológicos em suas tarefas diárias. Este estudo abordou a etapa inicial de um framework de integração de tecnologia na educação, que é parte do Programa de Integração de Tecnologia na Educação, desenvolvido pelo Laboratório de Experimentação Remota, na Universidade Federal de Santa Catarina. Neste estágio específico, conduziu-se uma pesquisa com o objetivo de conhecer o nível de conhecimento e experiência dos docentes participantes no que se refere ao uso de TICs em suas aulas. Dois questionários, disponibilizados no Ambiente Virtual de Ensino e Aprendizagem, foram respondidos por 398 professores de cinco escolas durante o estágio inicial das capacitações ofertadas pelo programa entre 2017-2019. Este estudo permitiu conhecer a visão dos docentes participantes quanto ao uso de tecnologias. É possível afirmar que o framework de formação tem se mostrado eficiente, uma vez que tem possibilitado aos professores aprenderem a utilizar as tecnologias em sala de aula bem como a refletir sobre as suas próprias práticas pedagógicas.
\end{abstract}

Palavras-chave: Tecnologia educacional. Educação Básica. Capacitação docente. TPACK.

\footnotetext{
${ }^{1}$ Universidade Federal de Santa Catarina (UFSC). Araranguá, SC, Brasil.<juarez.silva@ufsc.br>

${ }^{2}$ Universidade Federal de Santa Catarina (UFSC). Araranguá, SC, Brasil. < simone.bilessimo@ufsc.br>

${ }^{3}$ Universidade Federal de Santa Catarina (UFSC). Araranguá, SC, Brasil. <leticiarmachado@gmail.com> Educação em Revista|Belo Horizonte|v.37|e232757|2021
} 


\title{
INTEGRATION OF TECHNOLOGY IN EDUCATION: PROPOSAL FOR A TEACHER TRAINING MODEL INSPIRED BY TPACK
}

\begin{abstract}
Technological integration is typically understood as the incorporation of technology in classrooms. However, a key point of concern is how this inclusion has been made in the teaching process, learning experiences, and curriculum. Thus, it is possible to assert that the integration of ICT in the classroom involves specific teachers' skills concerning the pedagogical use of technologies. Teachers need to acquire and develop continuous relevant knowledge, competencies, and attitudes in order to include technological resources in their daily tasks. This research presents the initial stage of a framework for technology integration in education, which is part of the Program of Technology Integration in Education, developed by the Remote Experimentation Laboratory, at the Federal University of Santa Catarina. At this specific stage, a survey was conducted to understand the level of knowledge and experience in ICT of the participating teachers' in their classes. Two questionnaires made available in the Virtual learning environment were answered by 398 teachers from five schools during the initial teacher training course between 2017-2019. This study has enabled us to understand the participating teachers' perspectives on the use of technologies. It is possible to affirm that the presented training framework has been effective in enabling teachers to learn how to use technologies in the classroom and in helping them reflect on their pedagogical practices.
\end{abstract}

Keywords: Educational technology. Secondary education. Teacher training. TPACK.

\section{INTEGRACIÓN DE TECNOLOGÍA EN EDUCACIÓN: PROPUESTA DE UN MODELO DE FORMACIÓN DE PROFESORES INSPIRADO EN TPACK}

RESÚMEN: La integración tecnológica, aunque sea generalmente comprendida como la existencia de tecnología en los salones de clases, en verdad tiene como principal problema la necesidad de centrarse en cómo será esta inclusión al proceso de enseñanza, a las experiencias de aprendizaje y al currículo. Así, es posible afirmar que la integración de las Tecnologías de Información y Comunicación (TIC) en el salón de clase va por medio de competencias específicas de los docentes, cuanto al uso pedagógico de las tecnologías. Por lo tanto, los docentes deben tener conocimientos, habilidades y actitudes relevantes y que puedan desarrollarlas para incluir recursos tecnológicos en sus tareas diarias. Este estudio abordó la etapa inicial del framework de integración de tecnología en educación del Programa de Integración de Tecnología en Educación, del Laboratorio de Experimentación Remota, de la Universidad Federal de Santa Catarina. Esta etapa consistió como un diagnóstico, con el objetivo de conocer el grado de formación y uso de las TIC en clase por una parte de los docentes participantes. Los instrumentos utilizados fueron dos cuestionarios en línea, disponibles en el Ambiente Virtual de Enseñanza y Aprendizaje y que fueron respondidos durante el curso inicial de capacitación de los docentes. Los datos presentados en este documento se refieren a 398 profesores, de cinco escuelas, que participaron en las actividades de capacitación del programa entre 2015-2019. Este artículo permitió conocer la opinión de los docentes que participaron en la investigación sobre el uso de tecnologías. Es posible afirmar que el modelo de formación de la investigación ha demostrado ser eficiente, ya que ha posibilitado a los profesores solamente aprender a utilizar las tecnologías en el salón de clase y reflexionar sobre sus propias prácticas pedagógicas.

Palabras clave: Tecnología educacional. Educación Básica. Capacitación docente. TPACK. 


\section{INTRODUÇÃO}

A proximidade das Tecnologias da Informação e Comunicação (TIC) e o mundo educacional é evidente, se bem que por vezes esta aproximação responde mais a pressões externas à instituição de ensino (relacionadas com o fenômeno da sociedade de consumo que se vive e suas sucessivas modas) que a abordagens efetivamente didáticas e educacionais. Embora a integração tecnológica seja geralmente entendida como a existência de tecnologia nas salas de aula, na verdade, o principal problema deve se concentrar em como será essa inclusão da tecnologia ao processo de ensino, às experiências de aprendizado e ao currículo. Portanto, quando se fala em inovação educacional com as TIC, deve-se ter presente que essa não se fundamenta no uso crescente e indiscriminado das novas tecnologias, mas sim no desenvolvimento de práticas pedagógicas condizentes a seu uso em sala de aula.

Segundo Wenglinski (2005), a tecnologia educacional não deve ser observada como um fenômeno isolado, mas deve sim ser considerada uma peça do quebra-cabeça de como os professores ensinam e os alunos aprendem.

Assim, muitos pesquisadores educacionais indicam que a integração de tecnologia na sala de aula pode ser vantajosa para alunos e professores. Por exemplo, a tecnologia pode auxiliar a motivar os alunos e proporcionar-lhes habilidades importantes para reforçar seu aprendizado (BISSELL, 1998; BURNS, 2006; FELDSTEIN, 1988; NOVEMBER, 2010; PROJECT TOMORROW, 2010).

A inovação educacional, no terreno das TIC, passa por um conhecimento na prática dos limites e possibilidades que o protagonismo das mesmas pode ter nos processos de ensino e de aprendizagem. Segundo Haşlaman et al. (2007), quando as TIC estão integradas aos processos de ensino e de aprendizagem, isso significa que:

- os professores irão planejar e conceber ambientes e experiências de aprendizagem eficazes apoiados pelas TIC;

- os professores irão criar oportunidades de aprendizagem adequadas para a aplicação de estratégias de ensino que sejam enriquecidas pelas TIC, a fim de apoiar as necessidades dos alunos; e,

- aplicar planos de ensino que contenham métodos e estratégias necessários para o uso de tecnologias relevantes.

Inquestionavelmente, a integração das TIC na sala de aula passa por competências específicas dos docentes em relação ao uso pedagógico dessas tecnologias. Portanto, para que a integração desses recursos nas aulas seja mais efetiva, é necessário que os professores tenham conhecimentos, habilidades e atitudes pertinentes e que possam desenvolvê-las no intuito de incluir os recursos tecnológicos em suas tarefas diárias. Isto implica que o docente deve conhecê-las em suas dimensões, ser capaz de analisá-las criticamente e de realizar uma adequada seleção, tanto das tecnologias, como da informação que estes veiculam, sendo capaz de utilizá-las e realizar uma adequada integração curricular na sala de aula.

É possível então afirmar que as TIC afetam o perfil do docente na medida em que lhe exigem capacitação para sua utilização, além de cobrar destes uma atitude aberta e flexível ante às mudanças contínuas que ocorrem na sociedade como consequência do avanço tecnológico. Para muitos autores, uma das maiores dificuldades na hora de implementar as TIC na sala de aula, possivelmente não é saber usar uma ferramenta e sim definir para que utilizará a tecnologia.

O relatório Educadores, Tecnologia e Habilidades do Século XXI, publicado pela Universidade Walden, indicou que o problema, muitas vezes, é a dificuldade do docente em integrar tecnologia em sua classe e que está relacionada com à formação inicial. O documento cita que muitos professores acreditam que sua formação inicial não os preparou bem para qualquer tecnologia ou habilidades do século XXI.

Dados da pesquisa TIC Educação 2018, realizada pelo Comitê Gestor da Internet no Brasil (CGI.br), em relação aos docentes que atuam em escolas urbanas, indicaram que (CGI.BR, 2019):

- $55 \%$ não cursou, na graduação, alguma disciplina sobre o uso de computador e Internet em atividades de ensino;

- $70 \%$ não participou de curso de formação continuada sobre o uso de computador e internet em atividades de ensino; 
- $90 \%$ dos professores, quando questionados sobre a forma de aprendizado e atualização sobre o uso do computador e da internet, responderam "sozinhos".

Para obter sucesso em iniciativas de integração de tecnologia na educação, é necessário que os docentes sejam capazes de analisá-las criticamente, de realizar uma adequada seleção tanto dos recursos tecnológicos como da informação que estes veiculam, ser capazes de utilizá-las e realizar uma adequada integração curricular na sala de aula. Os dados apresentados anteriormente indicam carências na formação dos docentes em relação ao uso pedagógico da TIC. Essas carências irão se constituir em barreiras para a integração das TIC em seus planos de aulas. Neste sentido, a pesquisa TIC Educação 2018, sobre as barreiras percebidas pelos docentes de escolas urbanas, para o uso das TIC nas e

\section{MODELOS TECNO-EDUCACIONAIS}

A inclusão de tecnologias na prática educacional nem sempre é homogênea. Enquanto em algumas instituições é recebida com entusiasmo, em outras é recebida com incerteza, embora exista consenso sobre a importância de sua integração aos processos de ensino e de aprendizagem. A literatura apresenta diversos modelos para a integração das TIC na educação. Modelos estes que buscam atender ao nível didático das TIC e que estão relacionados a diferentes momentos no uso destas nos processos educacionais. Entre os diversos modelos citados na literatura podem ser incluídos os nomeados: ADDIE, ARCS, ASSURE, HYFLEX, THE DICK AND CAREY, ACOT, COI, ICM-FCM, ITL LOGIC, TIM, CONNECT, CLEs, FSM, OILM, SAMR e TPACK (GÁMEZ, 2015).

Os modelos orientados ao desenho instrucional ou ao ensino $\mathrm{EaD}$ buscam definir o processo instrucional como um sistema e apresentam uma variedade de ações ou etapas relacionadas visando o desenvolvimento de um processo educacional ordenado e compacto. Nesta linha de modelos podemos citar: ADDIE, ARCS, ASSURE, HyFlex e Modelo "The Dick and Carey Systems Approach Model".

O ADDIE, cujo nome se deve à adoção da letra inicial de cada uma de suas cinco fases: análise (Analysis), design (Design), desenvolvimento (Development), implementação (Implementation) e avaliação (Evaluation), é um modelo comumente usado no design instrucional. Foi desenvolvido na década de 1970 e, de acordo com Robin e McNeil (2012), sem autoria específica. Tem sido usado tanto na Educação quanto na indústria (ROBIN; MCNEIL, 2012; GÁMEZ, 2015).

O Modelo ARCS (attention, relevance, confidence e satisfaction, ou em português atenção, relevância, confiança e satisfação) foi apresentado no ano de 1987, por John Keller, e teve sua última versão apresentada em 2009 no livro: Motivational Design for Learning and performance. Este modelo parte da ideia de que existem características pessoais e ambientais que podem ter influência na motivação, e, portanto, no retorno diante de objetivos de caráter educacional. Sua concepção permite uma grande aplicabilidade em entornos de tecnologia virtual, e vem sendo utilizado de base na implementação de vários projetos de pesquisa (HUETT'; KALIWSKI; MOLLER; CLEAVES, 2008; JONES, 2010; LEE; KIM, 2012; GÁMEZ, 2015).

O modelo instrucional ASSURE foi desenvolvido, em 1992, por Robert Heinich, Michael Molenda e James D. Rusell. É um modelo apoiado na teoria de aprendizagem de Robert Gagné e leva em conta os nove eventos de instrução e processos cognitivos, propostos por ele. A saber: (i) obter atenção (recepção); (ii) informar o objetivo para os aprendizes (expectativa); (iii) estimular a lembrança do aprendizado anterior (recuperação); (iv) apresentar o estímulo (percepção seletiva); (v) fornecer orientação de aprendizado (código semântico); (vi) elucidar performance (resposta); (vii) fornecer feedback (reforço); (viii) avaliar o desempenho (recuperação) e (ix) aumentar a retenção e a transferência (generalização). A palavra ASSURE é um acrônimo para representar seis fases do desenho instrucional: A (analisar as características dos estudantes - Analyze learners); S ( Estabelecimento dos objetivos de aprendizagem - Set the objectives); S (selecionar as tecnologias, meios, métodos e materiais - Select the 3 M's); U (utilização destes meios, métodos e materiais (Utilize the 3 M' s); R (requerer a participação dos estudantes - Requiere learner participation) e .E (avaliar e revisar - Evaluate and review)( GÁMEZ, 2015). 
O modelo HyFlex foi proposto por Brian Beatty em 2006, na Convenção Anual Internacional de Tecnologia de 2006 da Association for Educational Communication. As palavras Híbrido e Flexível, que compõem o nome do modelo, dão uma ideia geral do que o autor tenta: oferecer ao aluno experiências de aprendizado, sejam virtuais ou presenciais. Isso constitui em uma proposta que fornece aos cursos de b-learning características de adaptação e flexibilidade em relação às individualidades para aprender e ao tempo exigido pelos alunos. É um modelo muito importante no campo da educação mediada por tecnologia (GÁMEZ, 2015).

O Modelo The Dick and Carey Systems Approach Model foi apresentado no ano 1978, por Walter Dick, Lou Carey e James O. Carey. Seus autores o propuseram como modelo para o ensino a distância. Seu fluxograma descreve um processo de 10 etapas ou componentes principais para apoiar o desenho, desenvolvimento, execução e avaliação do ensino, que, por sua vez, respondem a uma ordem predeterminada com uma estreita relação entre a realização de cada uma delas, onde a etapa anterior $\mathrm{O}$ modelo em geral estabelece "um processo sistêmico que se refere a seus componentes como um conjunto de partes inter-relacionadas, que juntas são direcionadas a uma meta definida e cada sistema depende de todo o sistema" (MARTÍNEZ, 2009).

Os modelos orientados ao desenvolvimento de ambientes podem ser identificados como aqueles direcionados ao desenvolvimento de ambientes de aprendizagem direcionados a uso específicos. Entre estes podem ser destacados os modelos: ACOT, COI, ICM-FCM, ITL LOGIC e TIM.

O Apple Classrooms of Tomorrow (ACOT) surgiu como um projeto de colaboração e investigação entre escolas públicas, universidades e agências de pesquisa, com o apoio da Apple Computer, Inc., que mostra excelentes resultados, por volta de 1995. O ACOT propôs o uso da tecnologia por professores e alunos, como um fator de mudança nos processos de ensino-aprendizagem. O projeto, que agora evoluiu para ACOT2 (Apple Classrooms of Tomorrow - Today), foi identificado como um modelo eficaz de ensino-aprendizagem com suporte tecnológico, desenvolvimento profissional de professores e disseminação de inovação (APPLE INC., 2008). As fases que compõem o modelo ACOT são Introdução, Adoção, Adaptação, Apropriação e Invenção e estão representadas na Figura 01 (DWYER, 1995).

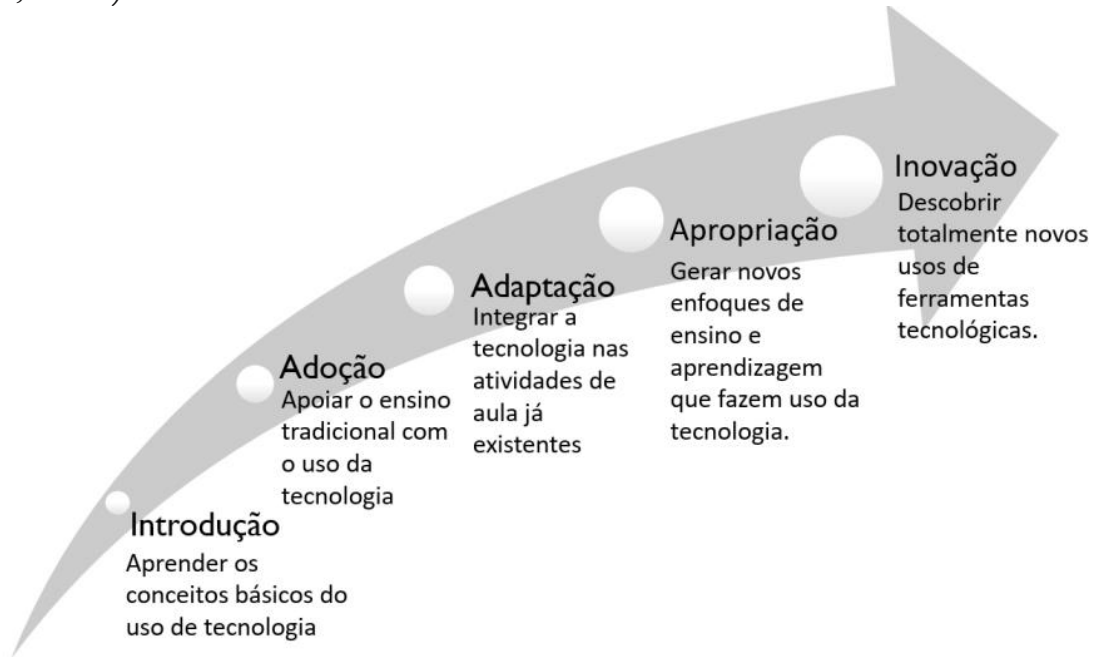

Figura 1 - Modelo ACOT.

Fonte: Adaptada de Dwyer (1995).

O modelo CoI (The Community of Inquiry Framework ou Modelo de Comunidade de Indagação), foi desenvolvido por Garrison, Anderson e Archer (2000), e tem sido um dos modelos tecnoeducacionais muito referenciado nos últimos anos. É um modelo criado para ambientes de e-learning, que propõe um design eficaz de experiência educacional em ambientes de aprendizado on-line e está baseado na aprendizagem social em comunidade, aprendizagem colaborativa, design instrucional, construtivismo social e educação a distância (TEKINER; SHUFORD, 2013). Procura compartilhar a visão de Vygotsky (1978) em seu caráter construtivista de acordo com a função da linguagem e do discurso como um meio de compartilhar a construção de significados. 
Modelo de aula invertida, Inverted ou Flipped Classroom Model (ICM/FCM ${ }^{4}$. Como o nome indica, sugere a inversão dos momentos e dos papéis no ensino tradicional, onde as atividades que o professor tradicionalmente transmite, podem ser assistidas em horário extra pelo aluno por meio de on-line ferramentas e as atividades em sala de aula executadas por meio de métodos interativos de trabalho colaborativo, aprendizagem baseada em problemas e realização de projetos (LAGE; PLAT'T; TREGLIA, 2000; TALBERT, 2012; GÁMEZ, 2015).

O Innovative Teaching and Learning (ITL) Logic Model ou Modelo Lógico Inovador de Ensino e Aprendizagem, foi desenvolvido pelo Instituto de Pesquisa Stanford (SRI), em 2009. Este modelo busca gerar novas habilidades de vida e trabalho em estudantes da Educação Básica, com base numa perspectiva da mudança nas políticas educacionais, mudança nas lideranças e culturas escolares que se refletirá em práticas educacionais inovadoras. O Modelo Lógico da ITL defende a premissa de que as TIC por si só não podem transformar a educação, que elas devem ser integradas a partir de uma perspectiva nacional, que as práticas de ensino devem ser pedagogicamente focadas na aprendizagem dos alunos (LANGWORTHY, 2014)

O modelo Technology Integration Matrix ou Matriz de Integración Tecnológica (TIM), foi desenvolvido por Jonassen, Howland, Moore e Marra (2003) e adaptado pelo Centro de Tecnologia Educacional da Flórida e Faculdade de Educação da Universidade do Sul da Flórida em 2011. A TIM é caracterizada pela aplicação de computadores pessoais, laptops, smartphones, tablets, quadros interativos, gravadores de $\mathrm{voz}$, ferramentas on-line como webquest, letterpop, entre outros, além de vídeos e áudios. As ferramentas de TIC permitem que a educação, o espaço, a localização e o tempo se adaptem aos usuários. No Modelo TIM, a interação entre professor e aluno é apenas mediada e não substituída pelas TIC, proporcionando um ambiente enriquecido em atividades, pesquisas, propostas, participação, troca de formas de estudo entre pares, independentemente de compartilharem espaços físicos, ou virtual. Porém, sem perder de vista o fato de que a maneira correta de ensinar pode superar a escolha incorreta das TIC, mas estas não podem substituir o mau ensino (BATES, 2005; GÁMEZ, 2015).

Os ambientes de aprendizagem desenhados tomando como base o modelo TIM têm as características da Figura 02.

\begin{tabular}{|c|}
\hline ATIVO \\
\hline COLABORATIVO \\
\hline CONSTRUTIVO \\
\hline AUTÊNTICO \\
\hline OBJETIVOS DIRIGIDOS \\
\hline
\end{tabular}

Figura 2 - Características dos ambientes de aprendizagem no modelo TIM.

Fonte: Traduzida da Matriz de Integração Tecnológica (http:// fcit.usf.edu/matrix/index.php).

Neste último grupo, o dos modelos que favorecem o uso de diversos recursos tecnológicos, são citados alguns modelos que abordam o uso de recursos ou meios tecnológicos diversos. Alguns baseados, principalmente, em teorias construtivistas e aprendizagem colaborativa. Neste grupo foram abordados os modelos: CONNECT, CLEs, FSM, OILM, SAMR e TPACK.

O modelo CONNECT sugere que os contextos e métodos de aprendizagem devem ser misturados. Define o uso do modelo de aprendizagem contextual, onde a importância dos contextos pessoais, físicos e socioculturais dos alunos é fundamental; define especificamente o papel da livre escolha do tipo de aprendizado. O modelo teve origem no CONNECT que foi cofinanciado pela Comissão Europeia no âmbito do programa IST - Information Society Technologies (AGOGI, 2006).

\footnotetext{
${ }^{4}$ O termo sala de aula invertida, foi originalmente cunhado por Lage, Platt e Treglia (2000) como sala de aula invertida (CI) e foi usado para detalhar a estratégia de aula implementada em uma disciplina específica (Economia), embora se refira ao uso de técnicas semelhantes em todas essas disciplinas em que o professor solicita a abordagem de tópicos específicos antes da aula (TALBERT, 2012; TUCKER, 2012).
} 
No modelo CONNECT o objetivo foi implementar as atividades propostas nas escolas por professores e educadores, sendo que originalmente foram concebidas sob o conceito de aprendizagem informal obtida em museus e parques científicos (GÁMEZ, 2015).

O modelo Constructivist Learning Environments (CLEs) ou Ambientes de Aprendizagem Construtivista, foi desenvolvido por David Jonassen em 1999 e seu principal objetivo é promover a resolução de problemas e o desenvolvimento conceitual; bem como enfatizar o papel do aluno na construção do conhecimento (aprender fazendo). O CLEs utiliza o design instrucional como modelo para projetar ambientes que envolvem os alunos no desenvolvimento do conhecimento, através da implementação dos elementos que o constituem.

O FSM (Five Stage Model of E-learning ou Modelo em Cinco Fases para Ensino e Aprendizagem on-line) foi desenvolvido por Gilly Salmon, em 2000, e consiste em cinco estágios ou fases para desenvolver o aprendizado no modo virtual com a ajuda de um moderador. Seu esquema representa uma escada na qual cada etapa expressa as habilidades acadêmicas, técnicas e de moderação envolvidas no aprendizado e ensino em uma comunidade virtual. Onde todos eles estão relacionados entre si através da interação entre seus elementos. A base teórica do modelo é constituída por: Próxima Zona de Desenvolvimento de Vygotsky, Construtivismo e Aprendizagem Cooperativa (ABDULLAH; HUSSIN; ASRA; ZAKARIA, 2013; GÁMEZ, 2015).

O Modelo de Aprendizagem de Interação on-line (do inglês Online Interaction Learning Model, ou OILM) foi proposto por Benbunan-Fich, Hiltz e Harasim, em 2005. Esse modelo tem sido aplicado como referencial teórico para cursos on-line e como modelo tecno-pedagógico no ensino superior. O modelo é baseado na teoria construtivista da aprendizagem, que promove a prática, a descoberta e a validação do conhecimento pelo aluno (BENBUNAN-FICH et al., 2005). Promovendo a combinação da participação do aluno com os processos de grupo interpessoal, os autores do modelo afirmam que essas interações estão relacionadas à medida em que a pedagogia da aprendizagem colaborativa é usada.

O modelo de Substituição, Aumento, Modificação e Redefinição (SAMR), foi desenvolvido por Rubén R. Puentedura e apresentado pela primeira vez na Conferência Internacional MERLOT4 (PUENTEDURA, 2003). O SAMR consiste em um conjunto hierárquico de 4 níveis que permite avaliar a maneira como as tecnologias são usadas por professores e alunos nas aulas. Seu objetivo é ajudar os professores a avaliar como eles estão incorporando tecnologias em suas salas de aula e, dessa maneira, sabendo que tipo de uso da tecnologia tem um efeito maior ou menor no aprendizado dos alunos (PUENTEDURA, 2012). A Figura 03 apresenta os quatro níveis que compõe o modelo SAMR. Podese observar que os dois primeiros níveis implicam uma melhoria tecnológica e os dois últimos uma transformação tecnológica.

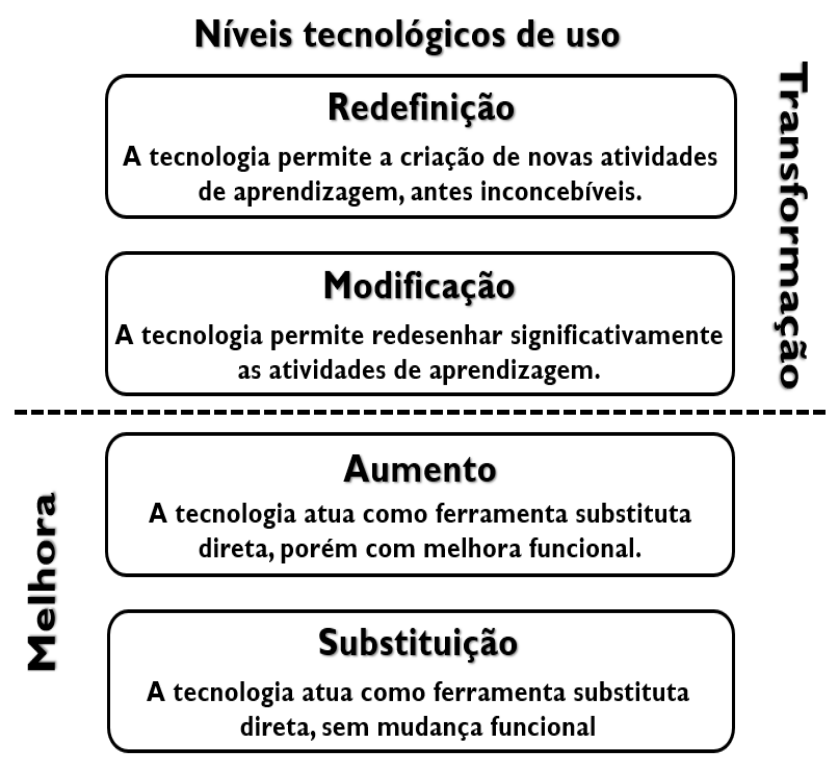

Figura 3 - Modelo SAM.

Educação em Revista|Belo Horizonte|v.37|e232757|2021 
Fonte: Tradução própria a partir de Puentedura (2012).

Finaliza-se esta seção com o modelo TPACK (Technological Pedagogical Content Knowledge ou Conhecimento Tecnológico Pedagógico de Conteúdo). Este modelo foi desenvolvido entre 2006 e 2009 pelos professores Punya Mishra e Mattew J. Koehler da Michigan State University. A proposta tem seus fundamentos iniciais no enfoque PCK desenvolvido por Shulman $(1986,1987)$ e ao qual foi agregado o termo de "Tecnologia" (T), aos já existentes "Pedagogia" (P) e "Conteúdo Curricular" (C). Levando em consideração as contribuições de Koehler e Mishra (2006) para que haja uma prática eficaz de ensino e conversas sobre boas práticas, elas devem se basear em três componentes básicos: Conteúdo curricular (CK - Content Knowledge), Pedagogia (PK - Pedagogical Knowledge) e Tecnologia (TK - Technological Knowledge) e todas as interações estabelecidas entre esses componentes. As interações entre esses componentes (CK, PK e TK) são a base do modelo TPCK.

Os autores Mishra e Koehler (2009) afirmam que as três áreas do conhecimento devem estar inter-relacionadas: Conteúdo (CK) localizado na área do conhecimento, disciplina ou disciplina ensinada e aprendida, segundo Mishra e Koehler (2006, p. 1026) “[...] é o conhecimento sobre o assunto a ser ensinado ou aprendido". O conhecimento Pedagógico (PK) destinado aos processos de ensino e aprendizagem, objetivos gerais, valores e metas de educação e tecnologia (CT) focados na assimilação das TIC para aplicá-las ao trabalho e à vida cotidiana. Este conhecimento tem origem nos campos da Pedagogia, Didática, entre outros, sendo o que é aplicado na aprendizagem do aluno. E o Conhecimento Tecnológico (TK), que abrange tecnologias tradicionais ou tecnologias digitais (MISHRA; KOEHLER, 2006)

Esses relacionamentos dão origem a quatro fatores: Conhecimento de conteúdo pedagógico (PCK); o conhecimento tecnológico do conteúdo (TCK); Conhecimento Tecnológico Pedagógico (TPK); alcançando para obter, o Conhecimento Pedagógico do Conteúdo Tecnológico (TPACK), onde o conhecimento do professor está vinculado, e avalia suas competências para poder transmitir determinada disciplina, tudo com uma abordagem significativa relacionada ao contexto de interação (KOEHLER; MISHRA, 2009). A Figura 04 identifica os três conjuntos de conhecimentos que interatuam uns com os outros e entre os três, constituindo novos tipos de saberes.

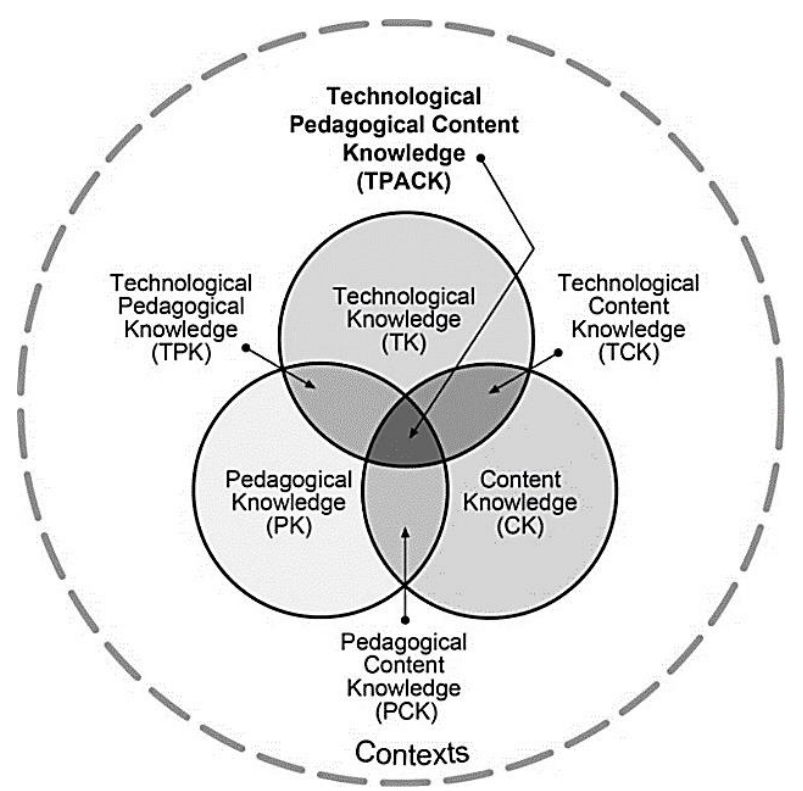

Figura 4 - Modelo TPACK.

Fonte: Baseado em http://www.tpck.org/

O Technological Pedagogical Content Knowledge (TPACK), ou Conhecimento Tecnológico Pedagógico de Conteúdo, é um modelo que busca identificar os tipos de conhecimento que um docente necessita dominar para integrar as TIC de uma forma eficaz no ensino que transmite. Sendo 
que seu principal objetivo é a articulação dos três conhecimentos que formam a sua base (CK, PK e TK), a fim de ser bem-sucedido nos objetivos de ensino e de aprendizagem.

O TPACK pode ser compreendido como um conjunto de estratégias que integram as tecnologias em sala de aula, sendo necessária a associação dos conhecimentos tecnológicos (Technological Knowledge - TK), pedagógicos (Pedagogical Knowledge - PK) e de conteúdo (Content Knowledge - CK) do professor. Assim, trata-se de um modelo pedagógico no qual o professor pode utilizar determinadas ações que possam se apoiar no uso das tecnologias na educação. No entanto, apesar de propor a integração das TIC nas escolas, os resultados atuais, conforme apontado anteriormente, exigem novas indagações e a necessidade de considerar como os programas de aplicação do TPACK poderiam apoiar melhor as práticas pedagógicas dos professores $(\mathrm{KOH}, 2019)$.

Segundo Harris et al. (2009), é muito importante que os professores procurem entender os domínios do TPACK, seus contextos e correlações. Deve-se atentar que não existe uma solução tecnológica única ou mágica, que irá funcionar em todos os contextos (professor, curso ou abordagem pedagógica). O sucesso para integração da tecnologia no âmbito educacional, está diretamente relacionado à flexibilidade e capacidade de trafegar pelos domínios dos conhecimentos de conteúdo, pedagógico e tecnológico, bem como as interações entre estes. Ignorar a complexidade inerente a cada componente de conhecimento ou suas relações, fatalmente levará ao fracasso da iniciativa.

É imprescindível que os professores desenvolvam fluência nos domínios principais (conteúdo, tecnologia e pedagogia) e não apenas em um ou parte deles. Ao conseguirem entender a forma como estes domínios se inter-relacionam, os docentes estarão ampliando as possibilidades de sucesso. Por exemplo, o TPACK considera que o conhecimento técnico é essencial para o ensino e a aprendizagem, porém, que este não é suficiente para promover mudanças nas formas de ensinar e aprender, uma vez que são necessários outros conhecimentos por parte dos professores. Para os docentes que escolham o ensino e aprendizagem mediada, principalmente, pelas tecnologias digitais, devem considerar a integração e a sobreposição dos domínios e subdomínios do TPACK, trabalhando-os em unicidade (HARRIS et al., 2009).

\section{METODOLOGIA}

O objetivo desse estudo foi desenvolver um modelo de capacitação docente utilizando para tanto o TPACK. Assim, a pesquisa teve uma abordagem quantitativa no intuito de coletar dados que pudessem responder a meta estabelecida no estudo. A escolha do tipo de abordagem se justifica à medida que foi necessário compreender de forma pontual e estruturado os dados coletados através dos instrumentos de coleta utilizados no processo, sendo possível generalizar resultados obtidos com os professores participantes da pesquisa.

A pesquisa foi realizada entre 2017-2019, sendo os participantes da pesquisa docentes que foram selecionados em escolas de Educação Básica, da rede pública estadual de Santa Catarina/Brasil, parceiras no Programa InTecEdu. Para adesão de uma nova instituição parceira ao Programa InTecEdu, inicialmente são efetuadas visitas e reuniões com os gestores das escolas, para apresentação do programa e contrapartidas do mesmo. Num segundo momento é feita uma palestra aos docentes da escola para apresentação do programa, sua abrangência e seus recursos. Uma vez feita a apresentação aos docentes, é dado um tempo para os mesmos demonstrarem seu interesse em participar. A adesão do docente ocorre com a sua participação em um curso semipresencial, com 130 horas/aula, denominado "Integração de tecnologias digitais em disciplinas da Educação Básica". Assim, a aplicação dos questionários e coleta dos dados ocorreu durante a realização deste curso e foram aplicados em formato on-line.

Para a coleta de dados foram utilizados dois questionários, ambos aplicados on-line, denominados "Questionário Perfil Docente" e "Questionário TPACK”. O questionário perfil docente", de construção própria do Programa InTecEdu, foi composto por 20 questões que buscaram caracterizar o perfil dos docentes participantes do programa. Este questionário, foi aplicado nos encontros iniciais, em 2017, 2018 e 2019, quando das ações de capacitação inicial realizadas através do curso "Integração 
de tecnologias digitais em disciplinas da Educação Básica". Foram realizadas ofertas anuais do curso, e neste documento estamos apresentando dados de três delas.

O questionário TPACK, teve como objetivo investigar a percepção de professores em relação a integração de tecnologia em suas aulas. Instrumentos para o diagnóstico, baseado no modelo TPACK, tem sido muito empregado existindo uma grande diversidade de modelos. O questionário TPACK, foi construído tomando como referência a pesquisa intitulada Survey of Teachers Knowledge of Teaching and Technology elaborada por Schmidt et al. (2009) que é uma pesquisa, composta de 54 itens de auto relato de mensuração dos professores, a respeito da percepção dos docentes sobre o ensino e a tecnologia. O questionário foi adaptado e validado no Programa InTecEdu, contendo 50 itens (vide Anexo A) elaborados a partir de uma revisão do modelo citado anteriormente e reescrito para a realidade do presente programa. Os 50 itens foram dispostos em uma escala de Likert de cinco pontos, vide Tabela 01, variando de discordância total (1) até a concordância total (5), a fim de, buscar avaliar a extensão em que os participantes concordam ou não com as declarações sobre as suas crenças sobre as relações entre tecnologia e ensino.

Tabela 1 - Escala de valores numéricos com pontuações.

\begin{tabular}{c|c|c|c|c}
\hline $\begin{array}{c}\text { Discordo } \\
\text { Totalmente } \\
\text { (DT) }\end{array}$ & $\begin{array}{c}\text { Discordo } \\
\text { Parcialmente } \\
\text { (DP) }\end{array}$ & $\begin{array}{c}\text { Sem Opinião } \\
\text { (SO) }\end{array}$ & $\begin{array}{c}\text { Concordo } \\
\text { Parcialmente } \\
\text { (CP) }\end{array}$ & $\begin{array}{c}\text { Concordo } \\
\text { Totalmente } \\
\text { (CT) }\end{array}$ \\
\hline 1 & 2 & 3 & 4 & 5 \\
\hline
\end{tabular}

Fonte: Elaborada pelos autores.

Após aplicação, os dados obtidos nos questionários foram categorizados de acordo com os domínios do TPACK. Assim os 50 itens foram distribuídos e categorizadas nas seguintes subescalas:

- Conhecimentos Pedagógicos (PK), 9 itens;

- Conhecimento do Conteúdo (CK), 5 itens;

- Conhecimento de Tecnologia (TK), 7 itens;

- Conhecimento Pedagógico do Conteúdo (PCK), 7 itens;

- Conhecimento do Conteúdo Tecnológico (TCK), 6 itens;

- Conhecimento Pedagógico Tecnológico (TPK), 8 itens; e,

- Conhecimento Pedagógico do Conteúdo Tecnológico (TPACK), 8 itens.

Para estimar a confiabilidade dos instrumentos, embora deve-se assinalar a existência de diferentes métodos para a obtenção do índice de confiabilidade, foi definido, para os dois questionários, o coeficiente Alfa de Cronbach. Segundo O’Dwyer e Bernauer (2014), o coeficiente Alfa de Cronbach muito utilizado para escalas tipo Likert, sendo um dos mais potentes. Além de ser o mais usual no âmbito da pesquisa em Tecnologia Educacional (BARROSO; CABERO, 2013), e que oferece mais flexibilidade para diversos tipos de dados que se pode encontrar (O’DWYER; BERNAUER, 2014). Este coeficiente mede a correlação entre respostas em um questionário, através da análise do perfil das respostas dadas pelos respondentes. Trata-se de uma correlação média entre perguntas (HORA, MONTEIRO, ARICA, 2010). O coeficiente alfa de Cronbach é uma medida comumente utilizada de confiabilidade (ou seja, a avaliação da consistência interna dos questionários) para um conjunto de dois ou mais indicadores de construto (BLAND, ALTMAN, 1997). Os valores de alfa variam de 0 a 1,0; quanto mais próximo de 1, maior é a consistência interna dos itens analisados. A confiabilidade da escala deve obter-se sempre com os dados de cada amostra para garantir a medida confiável do constructo na amostra concreta de investigação. Como critério geral, George e Mallery (2003) recomendam as seguintes indicações para avaliação dos coeficientes de alfa de Cronbach. 
Tabela 2 - Consistência interna do questionário segundo o valor de alfa.

\begin{tabular}{c|l}
\hline Valor do coeficiente alfa & Consistência Interna \\
\hline$>0.9$ & Excelente \\
\hline$>0.8$ & Bom \\
\hline$>0.7$ & Aceitável \\
\hline$>0.6$ & Questionável \\
\hline$>0.5$ & Pobre \\
\hline$<0.5$ & Inaceitável \\
\hline \multicolumn{2}{r}{ Fonte: George e Mallery (2003). }
\end{tabular}

Fonte: George e Mallery (2003).

O questionário destinado à coleta de dados sobre o modelo TPACK, foi aplicado ao final das ações de capacitação inicial realizadas através do curso "Integração de tecnologias digitais em disciplinas da Educação Básica", que ocorreram em 2017, 2018 e 2019. Os dados obtidos através da aplicação dos questionários auxiliaram na especificação das necessidades específicas de capacitação dos docentes. Neste sentido, foram desenvolvidas ações de capacitação/aperfeiçoamento específicas para cada grupo-alvo. E finalmente a articulação dos recursos tecnológicos com a experiência conceitual dos docentes e as necessidades identificadas nas disciplinas, que os docentes ministravam, frente ao processo de ensino dos conteúdos, com a construção de planos de aula que contemplaram estratégias de ensino reforçadas com recursos tecnológicos. A construção dos planos de aula foi inspirada no framework TPACK, que também contou com a realização das oficinas maker com os mesmos professores participantes anteriormente.

O contato inicial foi feito com gestores educacionais ou docentes interessados em participar das ações formativas. A ação seguinte a reunião com os gestores foi realizar uma apresentação, presencial na escola, do Programa IntecEdu a todos os docentes interessados no tema. Nesta apresentação buscou descrever o projeto, apresentar os interesses do grupo envolvido na pesquisa, bem como o papel dos possíveis participantes no projeto. Após este primeiro contato com os docentes, inicia-se o processo de adesão dos docentes que irão participar da primeira ação de capacitação, que é o curso semipresencial, com 130 horas/aula, denominado "Integração de tecnologias digitais em disciplinas da Educação Básica”.

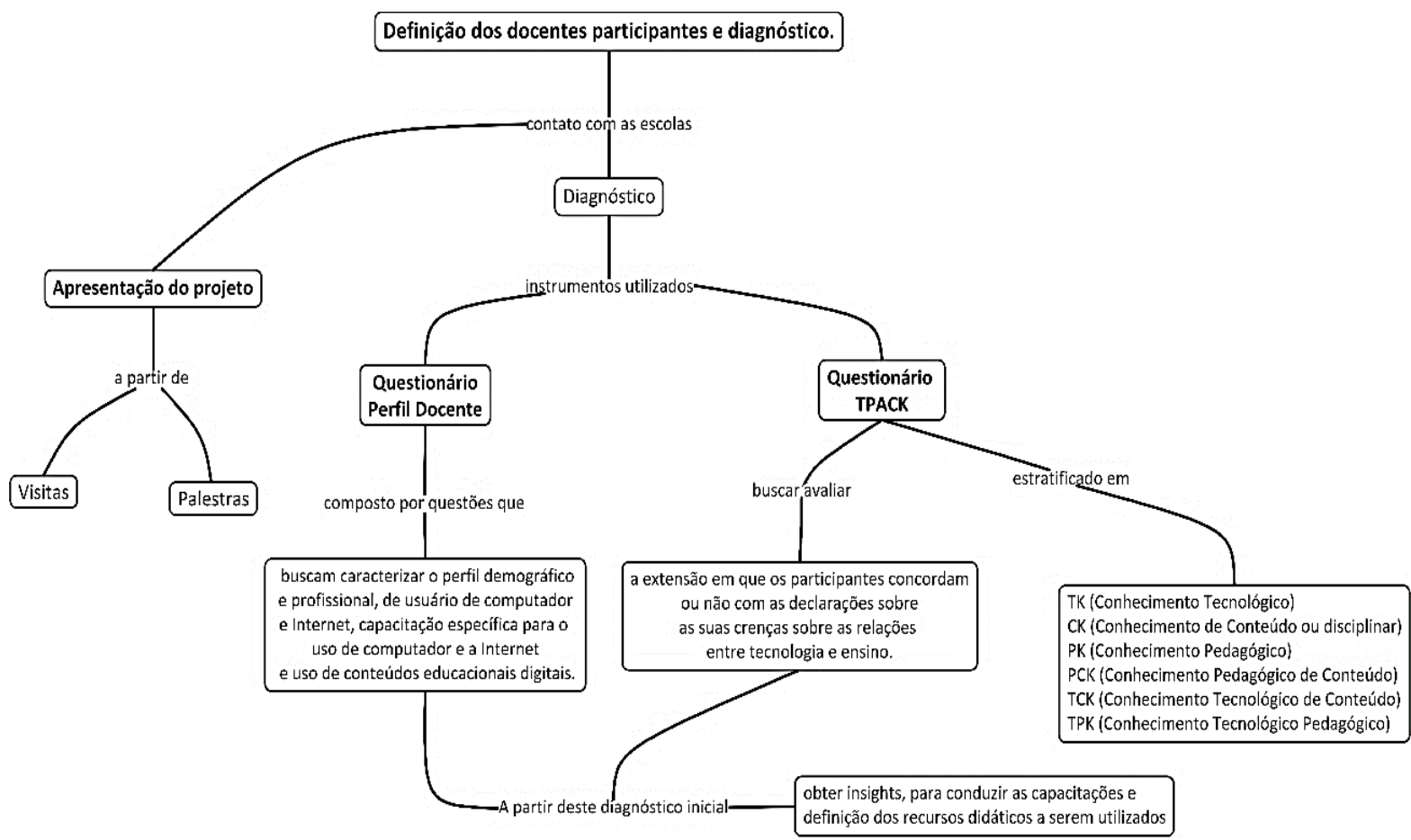

Figura 5 - Definição dos docentes e diagnóstico

Fonte: Elaborada pelos autores (2020).

Educação em Revista|Belo Horizonte|v.37|e232757|2021 
As ações seguintes de capacitação dos docentes foram precedidas de diagnóstico inicial que buscou analisar seus conhecimentos: tecnológico, pedagógico e de disciplinar/conteúdo. Para complementar os dados foi necessário também compreender como os professores pensavam a integração da tecnologia em suas salas de aulas. A partir deste diagnóstico inicial foram obtidos dados que auxiliaram na especificação das necessidades específicas de capacitação dos docentes. Neste sentido, foram desenvolvidas ações de capacitação/aperfeiçoamento específicas para cada grupo-alvo. E também que possibilitaram planejar a condução das especificações e requisitos dos recursos didáticos que seriam implementados e implantados nos planos de aulas.

Assim, considerando o diagnóstico realizado inicialmente, foi desenvolvido o modelo pensado para a capacitação dos docentes para integração de tecnologia nos planos de aulas, conforme apresentado na Figura 06.

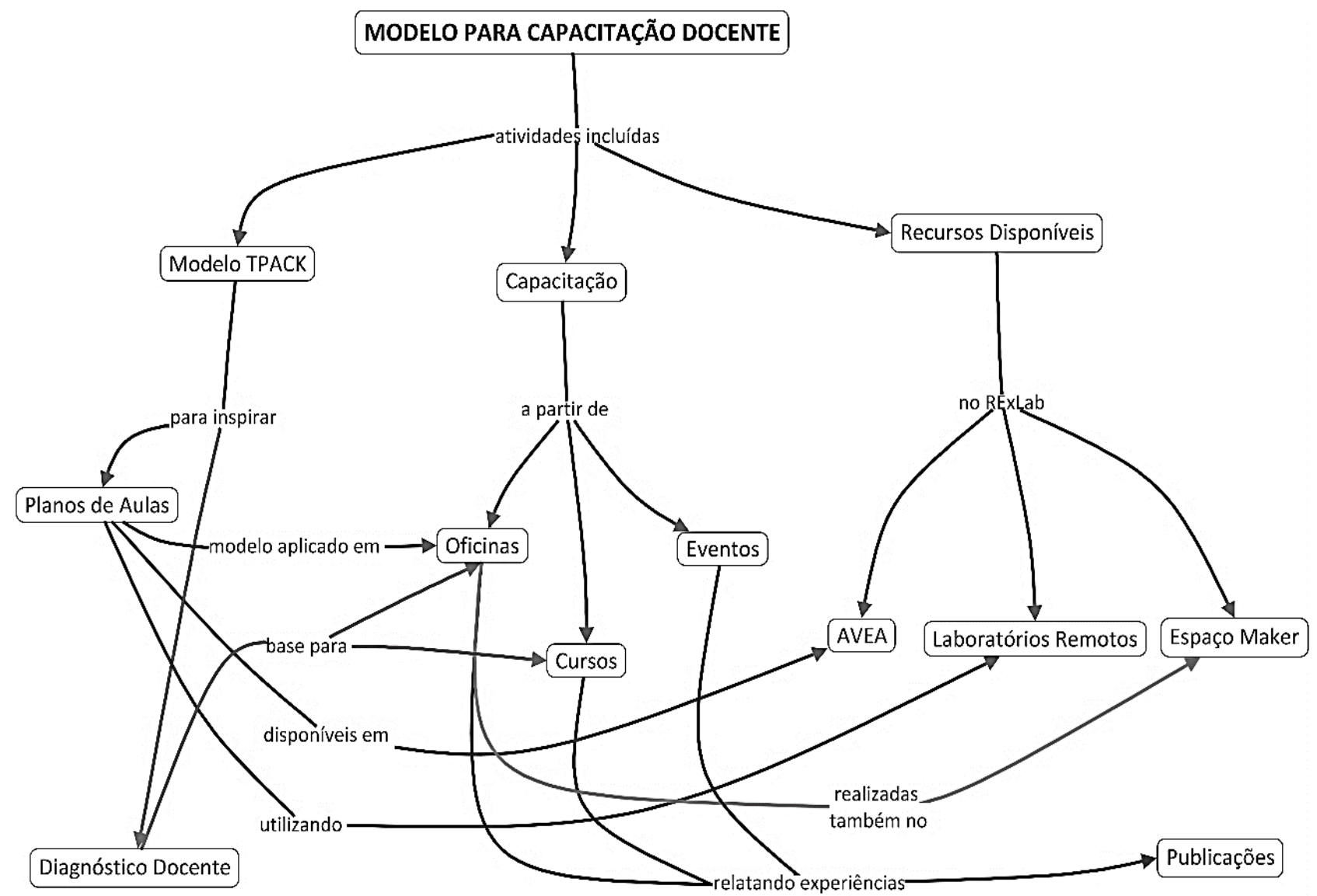

Figura 6 - Visão geral do modelo.

Fonte: Elaborada pelos autores.

O modelo contempla três grandes grupos, que considerou as atividades e os recursos necessários para a integração de tecnologia nos planos de aulas dos docentes participantes. O denominado modelo TPACK está relacionado com o diagnóstico inicial e a construção formal dos planos de aulas em uma perspectiva maker. Neste sentido o modelo buscou oportunizar aos docentes, que fossem os protagonistas da integração de tecnologia em seus planos de aulas. Uma vez que, estiveram encarregados de construir, produzir e disponibilizar aos seus alunos, os conteúdos digitais produzidos e outros recursos que deram suporte de suas atividades didáticas.

O segundo, denominado Capacitação, está relacionado com as atividades que viabilizaram a elaboração construção e também que objetivaram dar visibilidade aos planos de aulas construídos. A capacitação dos docentes teve sua formalização através da realização de cursos, on-line e semipresenciais, minicursos presenciais e on-line, oficinas e palestras que abordaram temas e estudos de casos referente a integração da tecnologia na educação. 
O terceiro esteve associado ao provimento dos recursos para construção dos planos de aulas. Os principais recursos utilizados foram providos pelo RExLab, através do ambiente virtual de ensino e aprendizagem, dos laboratórios virtuais e remotos e do espaço de fabricação e prototipação digital (makerspace).

Portanto, a próxima etapa foi desenvolver, detalhadamente, o percurso das atividades de capacitação dos docentes e disponibilização de planos de aulas, conforme apresentado na Figura 07.

Assim, uma vez definidos os docentes participantes, iniciou-se um curso semipresencial, com 130 horas, denominado "Integração de tecnologias digitais em disciplinas da Educação Básica". Para certificação os docentes tiveram que cumprir, pelo menos, $75 \%$ das atividades on-line, além de ter disponibilizado conteúdo digital, no AVEA, para pelo menos uma disciplina, das turmas, nas quais ministrava aulas.

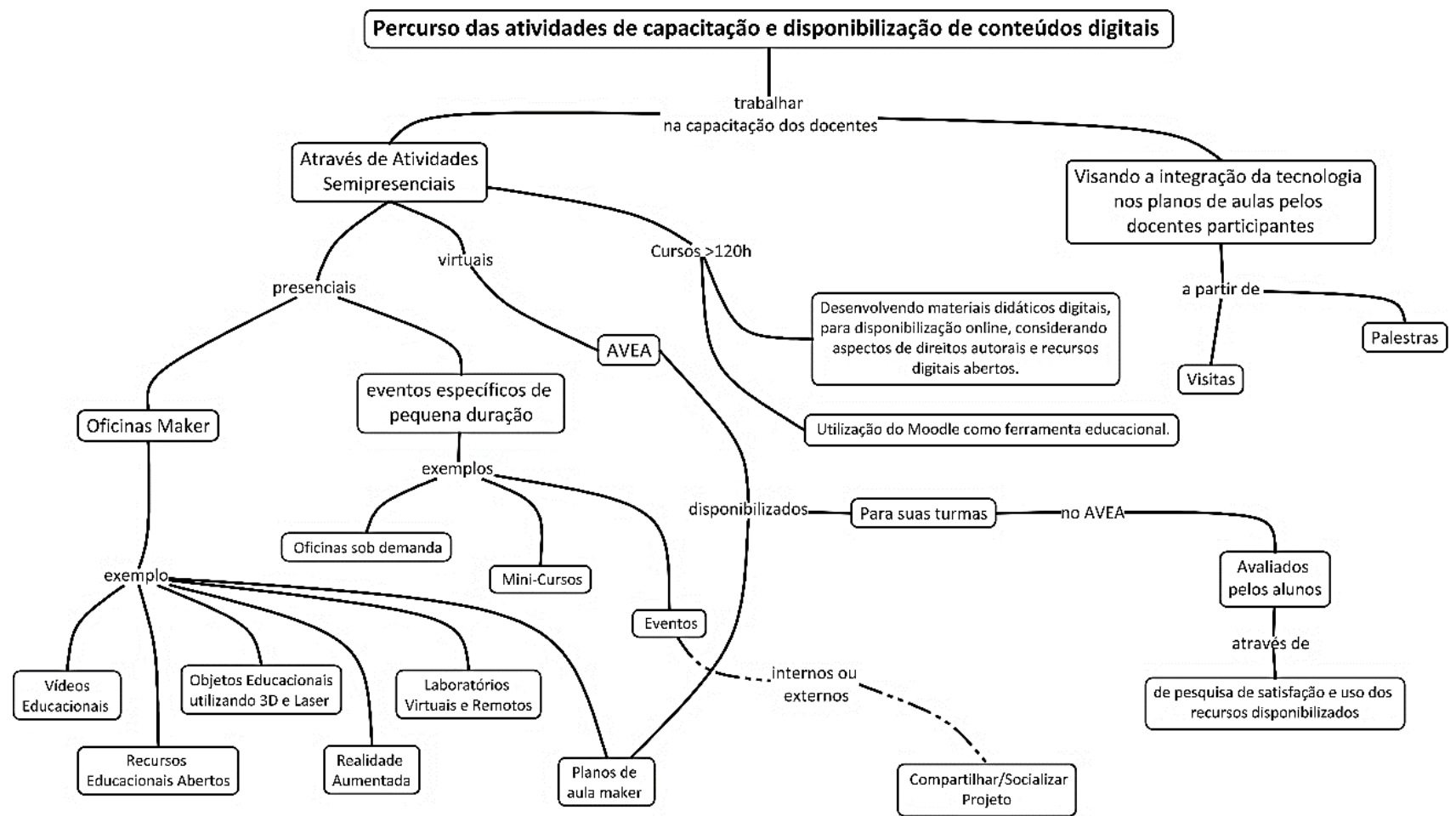

Figura 7 - Percurso das atividades de capacitação e disponibilização de conteúdos digitais.

Fonte: Elaborada pelos autores.

Após a conclusão do curso inicial de capacitação, foram desenvolvidas ações de capacitação/aperfeiçoamento, mais especificamente oficinas maker. E, finalmente, a articulação dos recursos tecnológicos com a experiência conceitual dos docentes e as necessidades identificadas nas disciplinas que os docentes ministravam e que contemplavam estratégias de ensino reforçadas com recursos tecnológicos. A construção dos planos de aula foi inspirada no framework TPACK, conforme apresentado anteriormente.

Com as ações de capacitação, esperou-se contribuir na formação dos docentes para um uso inovador da tecnologia fornecendo-lhes docentes a bagagem prática que lhes permitisse direcionar e planejar atividades de aprendizagem integrando tecnologia nos planos de aulas. O modelo desenvolvido buscou cumprir três etapas: apropriação tecnológica, estratégias de ensino e articulação dos recursos tecnológicos com a experiência conceitual dos docentes e as necessidades identificadas nas disciplinas, que os docentes ministram, frente ao processo de ensino dos conteúdos.

A etapa denominada "apropriação tecnológica" contemplou três níveis: acesso, adoção e apropriação da tecnologia:

-Nível de Acesso à Tecnologia: os docentes puderam identificar seu novo contexto educacional e buscaram desenvolver habilidades pedagógicas e tecnológicas para aplicá-las em novas estratégias de ensino. Neste sentido foi fundamental que os docentes adquirissem certas habilidades, 
conhecimentos e atitudes que os capacitaram para aplicar estratégias inovadoras e modelos para integrar a tecnologia nos processos de ensino e de aprendizagem.

-Nível de Adoção da Tecnologia: depois de identificar um novo método de trabalho com apoio da tecnologia, os docentes partiram para o uso das tecnologias em seus planos de aulas.

-Nível de Apropriação da Tecnologia: os docentes assumiram a integração da tecnologia em seus planos de aulas. Não é uma atitude definitiva, pois, está sujeita a um reforço progressivo.

A última fase se referiu à articulação dos recursos tecnológicos com a experiência conceitual dos docentes e as necessidades identificadas nas disciplinas, que os docentes ministravam, frente ao processo de ensino dos conteúdos. Nesta fase buscou-se motivar os docentes a considerarem fundamentalmente a construção de planos de aula contemplando estratégias pedagógicas reforçadas com recursos tecnológicos. A construção e aplicação dos planos de aula inspirada no framework TPACK foi o resultado obtido nesta fase.

\section{RESULTADOS E DISCUSSÃO}

O modelo de formação docente, do Programa InTecEdu, foi desenvolvido inspirado no TPACK e foi aplicado e avaliado com os professores que foram selecionados após as visitas e apresentação do programa às escolas interessadas. Em sua primeira etapa o modelo contempla um curso semipresencial, com 130 horas/aula, denominado "Integração de tecnologias digitais em disciplinas da Educação Básica". Neste curso os docentes necessitaram concluir, pelo menos, $75 \%$ das atividades online e disponibilizar conteúdo digital, no AVEA do Programa InTecEdu, em pelo menos uma disciplina que ministra. Quanto a distribuição da carga horária, 90 horas/aula são cumpridas no AVEA e 40 horas/aula em atividades presenciais, que são formalizadas através de oficinas presenciais sobre temas pontuais, por exemplo, a construção de objetos de aprendizagem no espaço maker do RExLab, utilização e prospecção de recursos digitais específicos, para uso educacional. Os docentes que cumprem os requisitos de conclusão do curso, recebem certificado de curso de extensão da Universidade Federal de Santa Catarina.

Esta pesquisa apresenta dados de três edições do curso realizadas anualmente, no período 2017-2019. Concluíram o curso inicial de capacitação 398 (45,02\%), de um total de 884 professores lotados nas escolas parceiras participantes. A saber cinco escolas da rede pública de ensino no estado de Santa Catarina.

Para tanto, fins de diagnóstico inicial, foram aplicados questionários on-line, disponíveis no AVEA onde estava disponível o curso inicial de capacitação. Os dois questionários, um denominado "Perfil Docente", buscou caracterizar o perfil dos professores e o segundo denominado "Questionário TPACK", buscou prospectar a percepção dos docentes relacionados aos seus conhecimentos: tecnológico, pedagógico e de disciplinar/conteúdo, e como estes integram a tecnologia em suas salas de aulas. Ou seja, buscou-se conhecer o grau de formação e de utilização, das TIC, em aula por parte dos docentes. A partir deste diagnóstico inicial foram obtidos alguns dados para condução das especificações e requisitos dos recursos didáticos que foram implementados nos planos de aulas.

Os dados obtidos a partir dos questionários aplicados aos docentes auxiliaram na especificação das necessidades de capacitação destes. Neste sentido, posteriormente, foram desenvolvidas ações de capacitação/aperfeiçoamento específicas para cada grupo-alvo. E finalmente a articulação dos recursos tecnológicos com a experiência conceitual dos docentes e as necessidades identificadas nas disciplinas, que os docentes ministravam, frente ao processo de ensino dos conteúdos, com a construção de planos de aula que contemplaram estratégias de ensino reforçadas com recursos tecnológicos. A construção dos planos de aula foi inspirada no framework TPACK, sendo que foi ministrada oficina presencial aos docentes relacionada a elaboração do plano de aulas, sob a perspectiva do framework utilizado e inspirado na cultura maker. Os planos de aulas elaborados nas oficinas presenciais, foram utilizados para disponibilização de conteúdos digitais, no AVEA do Programa InTecEdu, para os alunos dos docentes participantes.

A seguir serão apresentados e discutidos alguns dados dos dois questionários. Para tanto responderam o questionário "Perfil Docente" 362 (90,9\%) dos professores participantes, sendo 81,85\% 
do sexo feminino e 18,15\% masculino. A Figura 08 apresenta a distribuição por faixa etária. O maior percentual concentra-se na faixa etária de 36 a 40 anos (22,13\%), enquanto de 46,12\% tem idade superior e 53,88\% inferior a 40 anos, sendo que 19,25 idades inferiores a 30 anos.

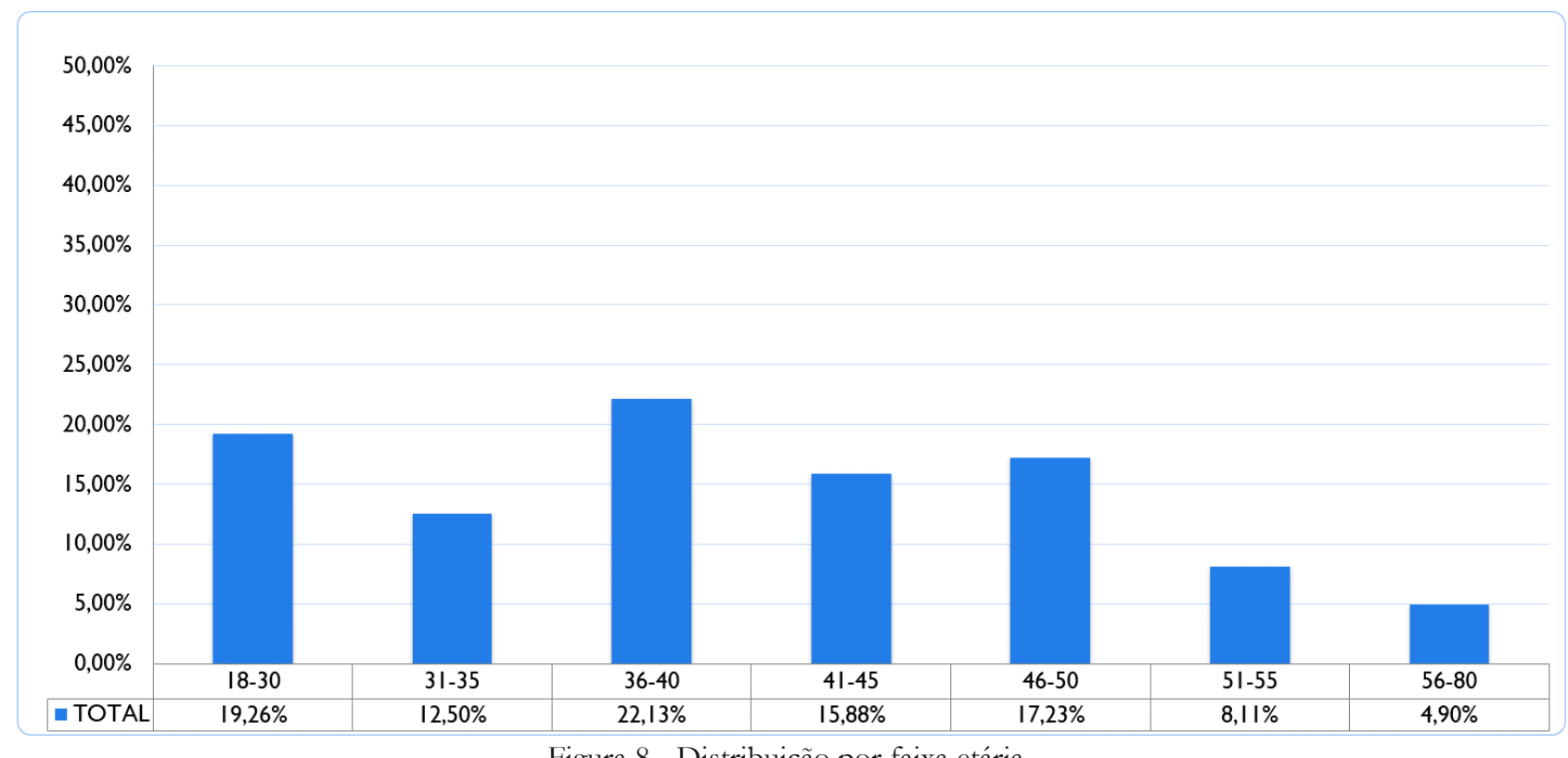

Figura 8 - Distribuição por faixa etária

Fonte: Elaborada pelos autores (2020).

A Figura 09 apresenta a distribuição dos docentes em relação a experiência como docentes na Educação Básica. Percebe-se equilíbrio entre as faixas propostas no gráfico. Sendo que 20,44\% dos docentes contam com mais de 20 anos e 79,56\% até 20 anos de atividade no magistério. E destes 39,02\% até 10 anos, sendo que 22,13\% têm menos de 5 anos de experiência no magistério.

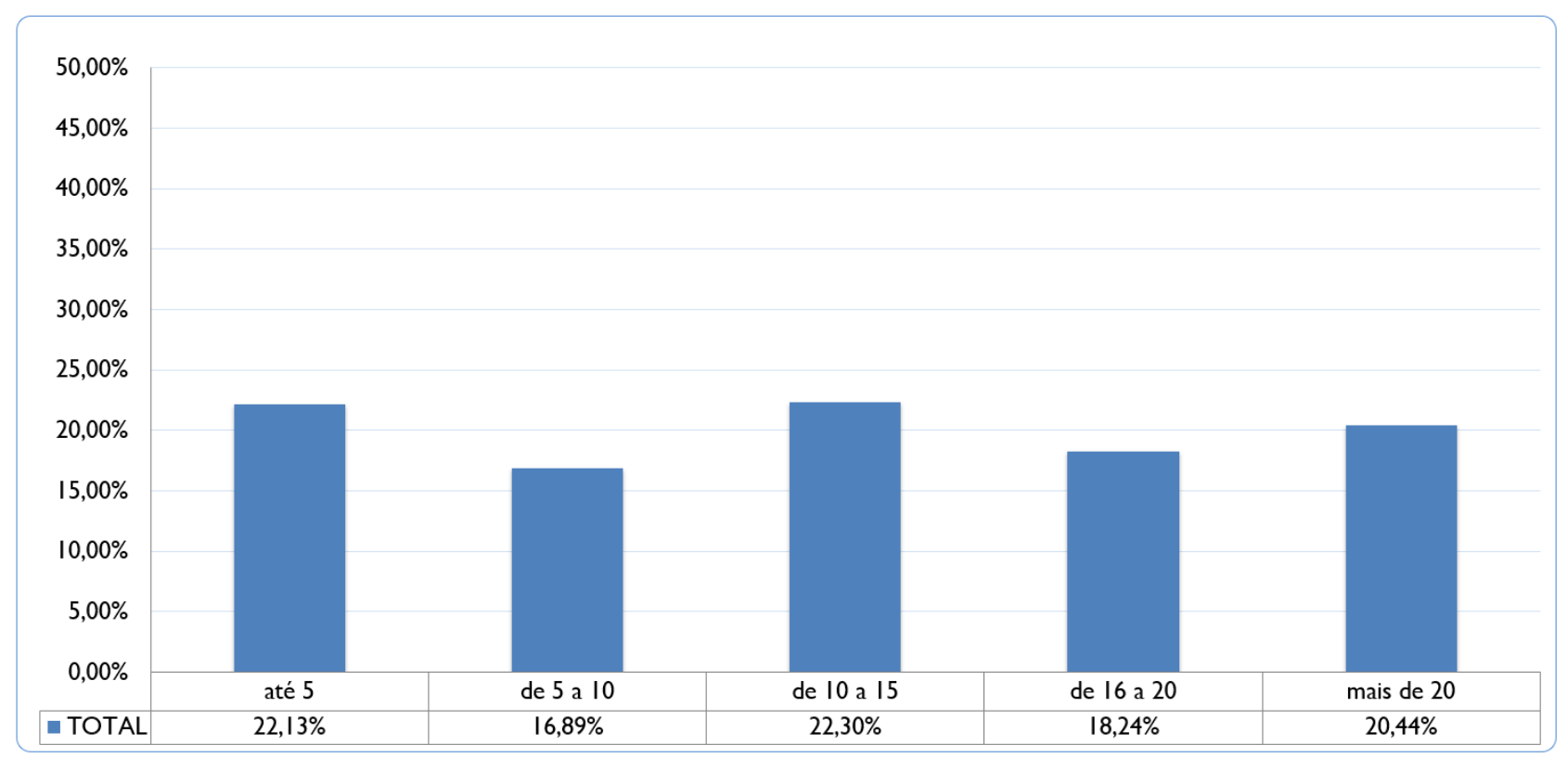

Figura 9 - Tempo de experiência no magistério.

Fonte: Elaborada pelos autores (2020).

Quando a formação, 96,33\% afirmaram ter cursado nível superior $(66,06 \%$ cursos de licenciatura, 19,27\% pedagogia). Em relação à pós-graduação, 81,15\% cursou em nível de especialização, 
2,08\% mestrado e 16,77\% não cursou. Quando a dependência administrativa das escolas que trabalhavam: $63,77 \%$ declarou na rede estadual, 32,26\% municipal e 4,30\% na rede federal, sendo que $59,76 \%$ eram efetivos/concursados e 40,24\% com contratos temporários. Quanto ao exercício da atividade profissional $64,88 \%$ declaram trabalhar em uma escola, $60,65 \%$ em duas e $4,46 \%$ em três ou mais. Em relação ao número de horas semanais dedicadas às aulas os dados apontam mais de 40 horas, conforme apresentado na Figura 10.

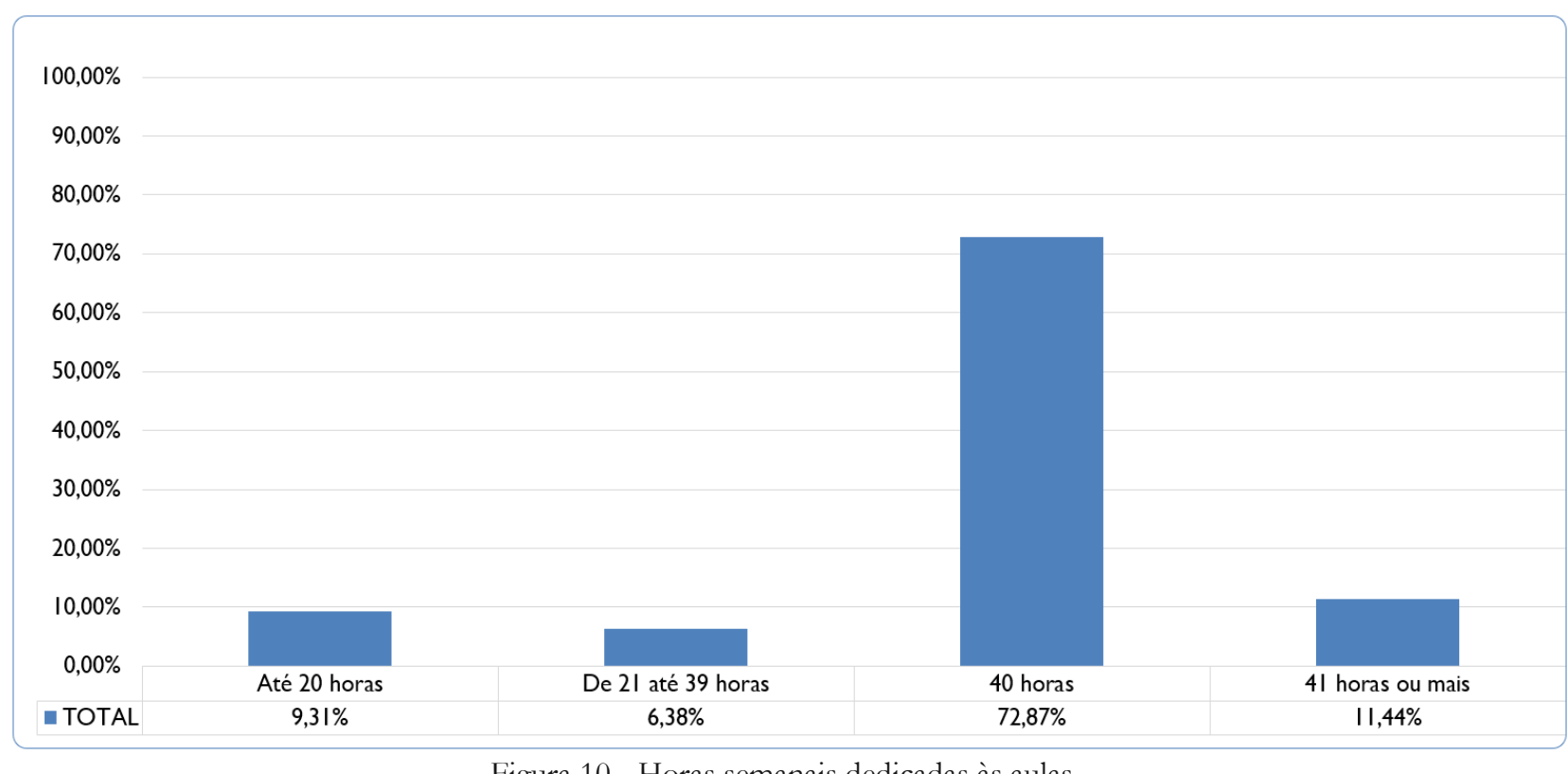

Figura 10 - Horas semanais dedicadas às aulas.

Fonte: Elaborada pelos autores (2020).

Em relação à tecnologia, apenas 1,69\% declarou não dispor de microcomputador e 60,28\% possuem computador portátil. Em relação a forma como aprendeu a utilizar o computador e Internet $33,67 \%$ responderam "sozinho" e 21,09\% que fizeram um curso específico.

Já os dados coletados em relação a algumas afirmações obtiveram os seguintes dados:

"Os alunos desta escola sabem mais sobre computador e Internet do que o professor. Você?", 92,59\% dos docentes assinalou "concordo totalmente" (27,95\%) e "concordo em parte" $(64,65 \%)$;

“Acredito mais nos métodos tradicionais de ensino. Você??", 43,54\% dos docentes assinalou "concordo totalmente" (0,68\%) e "concordo em parte" (42,86\%);

"Não sabe de que forma ou para quais atividades pode usar computador ou Internet na escola. Você?", 35,75\% dos docentes assinalou "concordo totalmente" $(13,61 \%)$ e "concordo em parte" $(22,21 \%)$ e $60,20 \%$ dos docentes assinalou "discordo totalmente" (37,71\%) e "discordo em parte" $(24,49 \%)$;

"Falta de apoio pedagógico para o uso de computador e Internet. Você?" 76,87\% dos docentes assinalou "concordo totalmente" (43,20\%) e "concordo em parte" (33,67\%);

"Falta de apoio pedagógico para o uso de computador e Internet. Você?", 76,87\% dos docentes assinalou "concordo totalmente" (43,20\%) e "concordo em parte" (33,67\%);

"Os professores não têm tempo suficiente para preparar aulas com o computador e a Internet. Você?", 70,41\% dos docentes assinalou "concordo totalmente" (34,35\%) e "concordo em parte" (36,05\%);

O questionário TPACK, foi aplicado ao final das ações de capacitação inicial realizadas através do curso "Integração de tecnologias digitais em disciplinas da Educação Básica", que ocorreram em 2017, 2018 e 2019. O "Questionário TPACK”, foi respondido por 361 (90,7\%) dos docentes que realizaram o curso inicial de capacitação. Os dados adquiridos no questionário foram agrupados, levandose em conta os sete domínios do TPACK e, conforme a Escala de Likert, foram alinhados os escores 
para cada um deles. O coeficiente de alfa de Cronbach apurado para o questionário aplicado, no seu total (50 itens), foi de 0,91. Considerado "excelente", de acordo com o critério geral de avaliação recomendado por George e Mallery (2003 ). A média dos escores na escala de Likert, para os 50 itens do questionário foi 3,65, em uma escala de 1 a 5, onde 1 representou "Discordo Totalmente" e 5 "Concordo Totalmente". O Desvio Padrão apurado para a média dos itens foi de 0,36 e Coeficiente de Variação de $9,88 \%$, considerado baixo e que indicando um conjunto de dados homogêneo. Os valores dos escores médios na escala de Likert aplicada para os domínios e subdomínios do TPACK são mostrados na Figura 11.

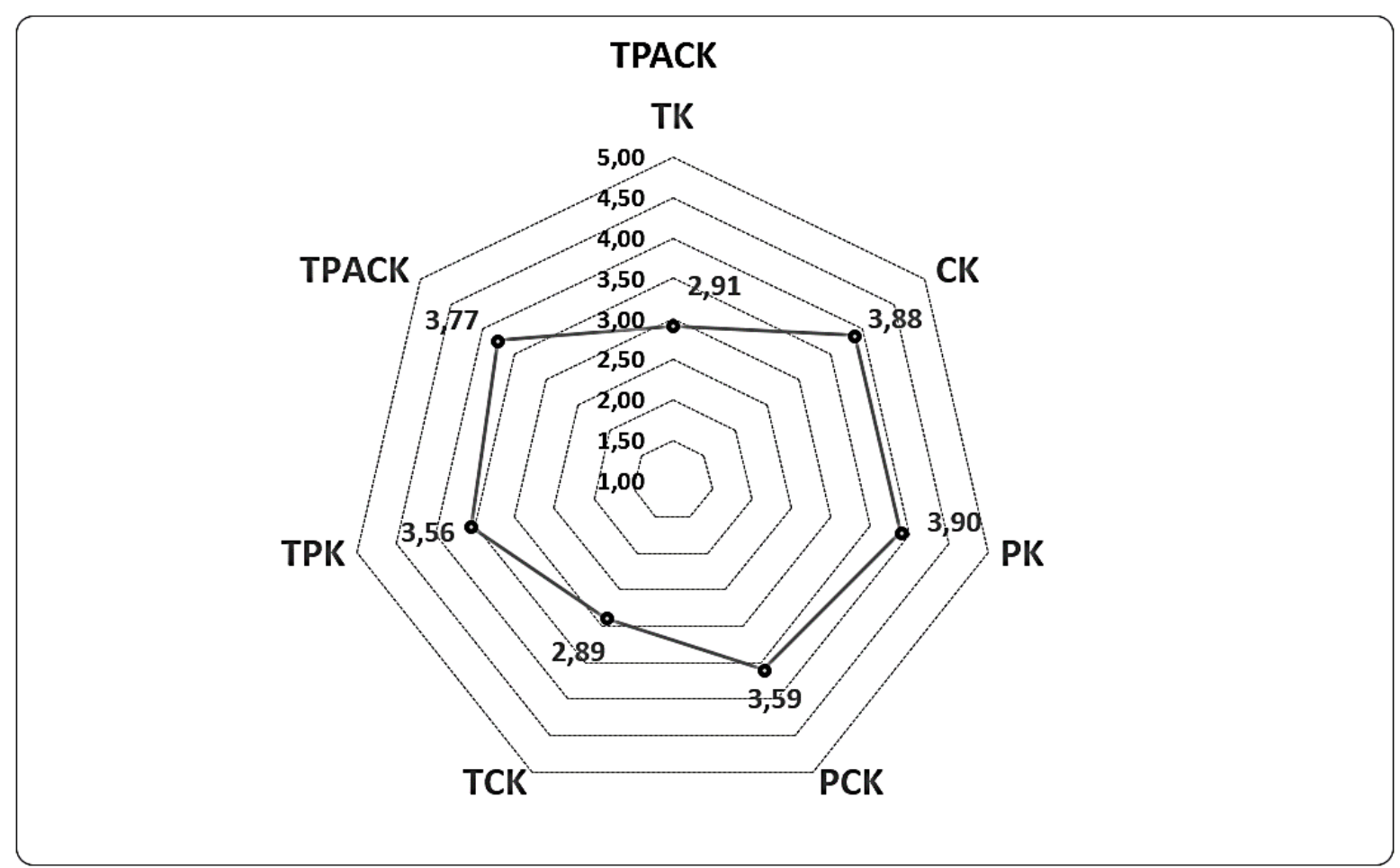

Figura 11 - Escores médios na escala Likert para os domínios e subdomínios TPACK.

Fonte: Elaborada pelos autores (2020).

Com base em Mishra e Koehler (2006), para um melhor entendimento do TPACK é necessário, inicialmente, compreender os três componentes que o compõem: o Conhecimento Pedagógico (PK), o conhecimento de conteúdo ou disciplinar (CK) e o Conhecimento Tecnológico (TK) e posteriormente suas relações. $\mathrm{O}$ PK é o conhecimento geral e as habilidades relacionadas com o ensino e incluem o conhecimento dos métodos de ensino geral. Essa está relacionado à compreensão das teorias educacionais de ensino e aprendizagem, ou seja, "o conhecimento que está envolvido em todas as questões relacionadas à aprendizagem dos alunos, gestão da sala de aulas, desenvolvimento e implementação dos planos de aulas e avaliação dos alunos" (MISHA; KOEHLER, 2006). O escore médio na escala de Likert de cinco pontos (1 a 5) aplicada, para os sete itens da subescala PK foi de 3,90. O coeficiente de alfa de Cronbach apurado para a subescala (7 itens), foi de 0,79 , o Desvio Padrão para a média dos itens foi de 0,18 e Coeficiente de Variação de 4,31\%. Em percentuais o valor médio para o PK foi de $83,10 \%$, somadas as respostas para as opções "concordo parcialmente" (73,7\%) e "concordo totalmente" (9,4\%).

O CK é o conhecimento dos atos, conceitos e conhecimentos que existem em um domínio em particular, por exemplo, são os conteúdos que se deve aprender nas aulas de Física no segundo ano do Ensino Médio. O CK é o conhecimento do assunto a ser tratado em sala, no qual o seu nível de aprofundamento difere de acordo com o grau de ensino, como exemplo temos a diferença do conteúdo de Termodinâmica abordado no ensino médio em relação ao superior. Desse modo, havendo uma necessária compreensão do professor da teoria e organização do seu desenvolvimento (SHULMAN, 1986). 
O escore médio na escala de Likert, para os sete itens de composição do CK, foi de 3,88. O coeficiente de alfa de Cronbach apurado para a subescala (7 itens), foi de 0,80, o Desvio Padrão para a média dos itens foi de 0,11 e Coeficiente de Variação de 2,93\%. Em percentuais o valor médio para o CK foi de 81,4\%, somadas as respostas para as opções "concordo parcialmente" (59,6\%) e "concordo totalmente" $(21,9 \%)$.

Já o TK é conhecimento necessário para compreender e utilizar as diversas tecnologias. Esse conhecimento está ligado ao entendimento sobre os aparatos tecnológicos, sua finalidade, funcionalidade, manuseio, entre outros. O conhecimento tecnológico está em constante mudança devido ao avanço contínuo das tecnologias e ele inclui a habilidade de aprendizagem e adaptação a uma nova tecnologia. Este contexto tecnológico abrange as TIC, os softwares de uso geral, a Internet e as tecnologias relacionadas, tais como, softwares educativos, simulações, ferramentas de modelagem, experimentação remota e muito mais (KOEHLER; MISHRA, 2008). O escore médio na escala de Likert, para os sete itens de composição do TK, foi de 2,91. O coeficiente de alfa de Cronbach apurado para a subescala (7 itens), foi de 0,76, o Desvio Padrão para a média dos itens foi de 0,47 e Coeficiente de Variação de 16,16\%. Em percentuais o valor médio para o TK foi de 37,6\%, somadas as respostas para as opções "concordo parcialmente" (33,9\%) e "concordo totalmente" (3,6\%).

O modelo TPACK propõe a interação entre os três tipos de conhecimento citados e que compõem o seu núcleo e que são os elementos constitutivos dos atuais entornos de aprendizagem. Para buscar esta interação o modelo TPACK necessita ir mais além de uma visão isolada dos três tipos de conhecimento que compõe, sendo necessário enfatizar as conexões e as complexas relações entre três dimensões de conhecimento (seus elementos constitutivos) o modelo define três novos tipos de conhecimento. Esse são: o Conhecimento Pedagógico de Conteúdo (PCK), o Conhecimento Tecnológico de Conteúdo (TCK) e o Conhecimento Tecnológico Pedagógico (TPK).

O PCK considera a Pedagogia $(\mathrm{P})$ e o conteúdo $(\mathrm{C})$ juntos para proporcionar o Conteúdo Pedagógico de Conteúdo, ou seja, a capacidade de ensinar um determinado conteúdo curricular. Segundo Shulman (1986), o PCK representa o conhecimento da pedagogia que é aplicável à instrução de conteúdo de uma ciência específica. Para Mishra e Koehler (2006), a ideia de conhecimento pedagógico do conteúdo é aplicável ao ensino de um conteúdo específico. O PCK inclui saber como os elementos do conteúdo podem ser organizados para melhoria do ensino. Este conhecimento é diferente daquele do especialista no conteúdo e também do pedagógico que é compartilhado por professores de diversas disciplinas. Assim, é voltado para a representação e formulação de conceitos, das técnicas pedagógicas, do conhecimento do torna difícil ou fácil aprender certos conceitos, do conhecimento das concepções alternativas dos alunos e das teorias da. O escore médio na escala de Likert, para os sete itens de composição do PCK, foi de 3,45. O coeficiente de alfa de Cronbach apurado para a subescala (7 itens), foi de 0,69, o Desvio Padrão para a média dos itens foi de 0,48 e Coeficiente de Variação de 13,98\%. Em percentuais o valor médio para o PCK foi de $62,0 \%$, somadas as respostas para as opções "concordo parcialmente" (57,6\%) e "concordo totalmente" (4,4\%).

O Conhecimento Conteúdo Tecnológico (TCK) é a relação mútua entre o conteúdo (C) e a tecnologia ( $\mathrm{T}$ ) sendo construído a partir da integração do Conhecimento Tecnológico (TK) e do Conhecimento de Conteúdo (CK), ou seja, saber selecionar os recursos tecnológicos mais adequados para comunicar um determinado conteúdo curricular. Este tipo de conhecimento é útil para descrever o conhecimento de um professor e de como o conteúdo didático de uma disciplina pode ser transformado através da aplicação de uma tecnologia. Um bom exemplo deste tipo são as simulações computacionais de fenômenos físicos que buscam ilustrar os conteúdos ao qual se relacionam. O escore médio na escala de Likert, para os sete itens de composição do TCK, foi de 2,79. O coeficiente de alfa de Cronbach apurado para a subescala (7 itens), foi de 0,86, o Desvio Padrão para a média dos itens foi de 0,35 e Coeficiente de Variação de 12,56\%. Em percentuais o valor médio para o TCK foi de 36,0\%, somadas as respostas para as opções "concordo parcialmente" (24,7\%) e "concordo totalmente" (3,3\%).

Já o Conhecimento Tecnológico Pedagógico (TPK) que se refere a compreensão geral da aplicação da tecnologia na educação sem fazer referência a um conteúdo específico, ou seja, saber usar esses recursos no processo de ensino e aprendizagem. O TPK inclui o conhecimento de como a tecnologia pode apoiar as estratégias pedagógicas específicas e/ou metas nas aulas. Um bom exemplo é 
a utilização de fóruns e sites de relacionamentos para fins pedagógicos, os quais não foram criados inicialmente com este objetivo. O escore médio na escala de Likert, para os oito itens do TPK, foi de 3,56. O coeficiente de alfa de Cronbach apurado para a subescala (8 itens), foi de 0,74 , o Desvio Padrão para a média dos itens foi de 0,27 e Coeficiente de Variação de 7,39\%. Em percentuais o valor médio para o TPK foi de 79,8\%, somadas as respostas para as opções "concordo parcialmente" (76,2\%) e "concordo totalmente" (3,6\%).

Por último, considerando conjuntamente os três novos tipos criados (PCK, TCK e TPK), teve-se Conhecimento Tecnológico Pedagógico de Conteúdo (TPACK). Koehler e Mishra (2006) sustentam que a verdadeira integração da tecnologia exige a compreensão e a negociação das relações entre estes três componentes do conhecimento.

O escore médio na escala de Likert, para os sete itens que compõem o TPACK, foi de 3,77. O coeficiente de alfa de Cronbach apurado para a subescala (7 itens), foi de 0,73, o Desvio Padrão para a média dos itens foi de 0,28 e Coeficiente de Variação de 7,65\%. Em percentuais o valor médio para o TPACK foi de 78,7\%, somadas as respostas para as opções "concordo parcialmente" $(63,5 \%)$ e "concordo totalmente" (6,6\%). O ensino eficaz e eficiente não é simplesmente acrescentando a tecnologia e o domínio de um conteúdo existente na sala de aula, porém, a introdução da tecnologia poderá possibilitar novas representações de conceitos (KOEHLER, MISHRA, 2007; SCHMIDT, SAHIN, THOMPSON, SEYMOUR, 2008; SCHMIDT, BARAN, THOMPSON, MISHRA, KOEHLER, SHIN, 2009).

Entre os 398 docentes que concluíram o curso, 67 (16,84\%) continuaram a utilizar os recursos em suas classes, conforme apontados pelos participantes no questionário aplicado. Esses produziram e disponibilizaram conteúdos didáticos, por eles produzidos, no AVEA do Programa InTecEdu, para 224 turmas com o atendimento de 6.570 alunos. Esse número alcançou 61,64\% do total de alunos matriculados (10.659), no ensino fundamental e médio, nas escolas participantes. Estes dados foram coletados no AVEA, uma vez que, tanto o curso de capacitação, quanto as turmas disponibilizadas pelos docentes estão no ambiente virtual do programa.

Em relação à integração de tecnologia nas áreas STEM, 29 professores, 67,44\% dos professores identificados com atuação na área disponibilizaram seus conteúdos didáticos. Os conteúdos atenderam 3.360 alunos, de 98 turmas de 9 escolas. Esses tiveram, entre outros recursos, o acesso a Laboratórios Virtuais e Remotos, em planos de aulas em disciplinas de Física e Biologia (Ensino Médio), Ciências (Ensino Fundamental). Para apoiar as atividades práticas nas áreas STEM, foram disponibilizados 20 laboratórios remotos, com 26 instâncias, para utilização em atividades práticas em disciplinas [ http://relle.ufsc.br/labs ].

Portanto, considerando os dados coletados, pode-se observar a necessidade de uma formação docente adequada para a nova realidade de sociedade e a contribuição do modelo TPACK para as práticas pedagógicas que se apoiem nas TIC. Os dados coletados permitiram compreender um pouco mais sobre os professores que estão atuando nas escolas estaduais de Santa Catarina, bem como os desafios em incluir os recursos tecnológicos na sala de aula da Educação Básica.

\section{CONSIDERAÇÕES FINAIS}

A sociedade está se transformando tecnologicamente e isso está se refletindo nas escolas. Assim, cada vez mais é necessário considerar novas metodologias e estratégias pedagógicas que possam incluir as tecnologias nas práticas pedagógicas. No entanto, apesar de existir essa necessidade, o que se observar é pouco uso dos recursos tecnológicos em sala de aula, possibilitando que muitas indagações sobre os motivos sejam realizadas.

Nesse contexto, o presente estudo pode compreender as necessidades dos alunos e demandas dos professores no que diz respeito ao uso das TIC na sala de aula. Esse artigo teve como objetivo apresentar e avaliar um modelo de capacitação docente para o uso das TIC em sala de aula utilizando, para tanto, o TPACK. Nesse sentido, foi possível realizar um levantamento sobre o modelo de formação docente aplicado no decorrer do processo dessa pesquisa, assim como sobre a visão dos professores que participaram da investigação sobre o uso das tecnologias. 
Os dados coletados no diagnóstico apontaram que os professores sabem manusear e compreender como utilizar as tecnologias na sala de aula. No entanto, ainda há dúvidas sobre os métodos mais eficazes para o ensino. Esse tipo de dado aponta uma defasagem no que diz respeitos às demandas que os alunos trazem para a sala de aula e o que os professores consideram mais pertinente. Cabe ressaltar que as respostas dos professores correspondem a um contexto que possuem diferentes elementos que podem influenciar nos apontamentos, sendo pertinente, em um futuro estudo, aprofundar sobre essa temática.

Já em relação ao modelo TPACK observou-se que os professores ainda possuem dificuldade no que diz respeito ao seu uso em sala de aula, apesar de que, inicialmente, terem respondido que tinha conhecimento de como e quando aplicá-los. Assim, o modelo de formação proposto na pesquisa se mostrou eficiente, uma vez que possibilitou aos professores não apenas aprenderem a utilizar as tecnologias em sala de aula, mas também refletir sobre as suas próprias práticas pedagógicas. Essa utilização em sala de aula ficou evidente pelos dados no uso das TIC após a pesquisa, apesar de pequeno, mas relevante para apontar mudanças iniciadas no processo de ensino e aprendizagem

Esse estudo pode auxiliar na compreensão que ainda há muito o que investigar sobre a temática e que os professores necessitam, cada vez mais, de formações docentes para que possam compreender e distinguir os modelos mais pertinente, ou não, que englobam os preceitos da nova sociedade conectada e tecnológica.

\section{REFERÊNCIAS}

ABDULLAH, Muhammad; HUSSIN, Zaharah, Asra; ZAKARIA, Abd Razak. mLearning Scaffolding Model for Undergraduate English Language Learning: Bridging Formal and Informal Learning. Turkish Online Journal of Educational Technology - TOJET, 12(2), 217-233, 2013.

AGOGI, Ellinogermaniki. Visualizing the invisible: the CONNECT approach for teaching science. 2006. Disponível em: http://goo.gl/JK0b0E . Acesso em: 10 dez. 2019.

ALMEIDA, Diogo; SANTOS, Marco; COSTA, Antonio. (2010). Aplicação do coeficiente alfa de cronbach nos resultados de um questionário para avaliação de desempenho da saúde pública. XXX Encontro Nacional de Engenharia de Produção, 2010. Disponível em: http://www.abepro.org.br/biblioteca/enegep2010_TN_STO_131_840_16412.pdf Acesso em: 03 jan. 2020 .

APPLE Inc. Apple Classrooms of Tomorrow: Learning in the 21st Century. 2008. Disponível em: http://ali.apple.com/acot2/global/files/ACOT2 Background.pdf Acesso em: 02 nov. 2019.

BARROSO, Julio Manuel; CABERO, Julio. Nuevos escenarios digitales. Madrid: Pirâmide, 2013.

BATES, Tony. Technology, E-Learning and Distance Education, $2^{\mathrm{a}}$ Ed. New York: Routledge. 2005

BRASIL. (2018). Censo Escolar da Educação Básica MEC/INEP 2018. Brasília: Ministério da Educação, 2018. Diponível em: http://portal.inep.gov.br/informacao-da-publicacao//asset_publisher/6JYIsGMAMkW1/document/id/1487619 Acesso em: 03 jan. 2020.

BEATTY, Brian. (2013). Hybrid-Flexible Course Design: Implementing student-directed hybrid classes. $1^{a}$ Ed., EdTech Books. 2019. Disponível em: https://edtechbooks.org/hyflex Acesso em: 03 jan. 2020.

BENBUNAN-FICH, Raquel; HILTZ, Starr Roxanne; HARASIM, Linda M. (2005). The Online Interaction Learning Model: Na Integrated Theoretical Framework for Learning Networks. Em S. R. 
Hiltz and R. G. Goldman (Eds.), Learning together online, Research on Asynchronous Learning Networks. (pp. 18-36). Mahwah, New Jersey: Lawrence Erlbaum Associates.

BISSELL, Patricia. M. Tune in to Technology. Music Educators Journal, 85(2), 36-41, 1998.

BLAND, J. Martin; ALTMAN, Douglas. G. Statistics notes: Cronbach's alpha. British Medical Journal, London: 314, n.7080, p. 572, 1997.

BURNS, Amy. M. Integrating Technology into Your Elementary Music Classroom. General Music Today, 20(1), 6. 2006.

GEORGE, Darren; MALLERY, Paul. SPSS for Windows step by step: A simple guide and reference. Disponível em

https://wps.ablongman.com/wps/media/objects/385/394732/george4answers.pdf. Acesso em 10/jun/2019.

CGI.BR. (2019). Pesquisa sobre o uso das tecnologias de informação e comunicação no Brasil TIC Educação 2018. São Paulo: CGI.BR.

DICK, Walter; CAREY, Lou; CAREY, Lou. (1978). The Systematic Design of Instruction. Glenview, Il, USA. Disponível em http://www.schoolofed.nova.edu/dll/Module2/Module3-1-DickandCarey.pdf Acesso em 20 dez. 2019.

DWYER, David. (1995). Changing the Conversation About Teaching Learning \& Technology: A Report on 10 Years of ACOT Research. Disponível em http://imet.csus.edu/imet1/baeza/PDF\%20Files/Upload/10yr.pdf Acesso em 15 nov. 2019.

FELDSTEIN, Shelah. Technology for teaching. Music Educators Journal, 74(7), 35-37. 1998.

GÁMEZ, Ismael Esquivel. Los Modelos Tecno-Educativos, revolucionando el aprendizaje del siglo XXI. México. Primeira edição. 2015. Disponível em http://www.eduteka.org/articulos/modelostecno-educativos Acesso em 02 jan. 2020.

HARRIS, Judith., MISHRA, Punya, Koehler, Matthew. Teachers' technological pedagogical content knowledge and learning activity types: Curriculum-based technology integration reframed. Journal of Research on Technology in Education, 41(4), 393-416, 2009. Disponível em http://www.eric.ed.gov/PDFS/EJ844273.pdf Acesso em 10 dez. 2019.

HAŞLAMAN, Tülin; KUŞKAYA-MUMCU, Filiz; KOÇAK-USLUEL, Yasemin. The integration of Information and Communication Technologies in learning and teaching process: A lesson plan example. Education and Science, 32(146), 54-63, 2007.

HEINICH, Robert; MOLENDA, Michael, RUSSELL, James D.; SMALDINO, Sharon E. Instructional media and technologies for learning. $7^{\mathrm{a}}$ Ed. Merrill Prentice Hall, 2002.

HORA, Henrique R.; MONTEIRO, Gina. T.R.; ARICA, José. Confiabilidade em Questionários para Qualidade: Um Estudo com o Coeficiente Alfa de Cronbach. Produto \& Produção, Porto Alegre, v. 11, n. 2, p.85-103, jun. 2010. Disponível em:

<http://www.seer.ufrgs.br/ProdutoProducao/article/viewFile/9321/825>. Acesso em: 31 nov. 2017.

HUETT, Jason Bond; KALINOWSKI, Kevin; MOLLER, Leslie; CLEAVES, Kimberly. Improving the Motivation and Retention of Online. The American journal of Distance Education, 22(3), 159-176, 2008. DOI: $10.1080 / 08923640802224451$ 
JONASSEN, David. (1999). Designing constructivist learning environments. In C. M. Reigeluth (Ed.), Instructional design theories and models: A new paradigm of instructional theory, 2, 215-239. Mahwah, NJ: Lawrence Erlbaum Associates. 1999. Disponível em http://www.davidlewisphd.com/courses/EDD8121/readings/1999-Jonassen.pdf Acesso em 08 out. 2019.

JONASSEN, David; HOWLAND Jane; MOORE, Joi; MARRA, Rose. Learning to solve problems with technology: A constructivist perspective (2a Ed.). NJ: Merrill Prentice Hall, 2003.

JONES, Brett. Estudio de componentes de un modelo de motivación en la enseñanza presencial y online. Electronic Journal of Research in Educational Psychology, 8(22), 915-944, 2010.

KOEHLER, Matthew; MISHRA, Punya. (2009). What is technological pedagogical content knowledge? Contemporary Issues in Technology and Teacher Education, 9(1), 2009. Disponível em http://www.citejournal.org/vol9/iss1/general/article1.cfm Acesso em 12 dez. 2019.

KOEHLER, Matthew; MISHRA, Punya. (2008) Introducing technological pedagogical content knowledge. Em AACTE committee on innovation and technology (ed.), handbook of technological pedagogical content knowledge (TPCK) for educators (pp. 3-29). New York: Routledge. 2008.

$\mathrm{KOH}$, Joyce Hwee Ling. TPACK design scaffolds for supporting teacher pedagogical change. Educational Technology Research and Development, 67(3), p 577-595, 2019.

LAGE, Maureen; PLATT, Glenn; TREGLIA, Michael. Inverting the classroom: A gateway to creating na inclusive learning environment. The Journal of Economic Education, 31(1), 30-43, 2000.

LANGWORTHY, Maria. Beyond Heroes: Innovative Teaching and Learning. UNESCO ICT \& Education Conference, Brasília, Brasil, 2014. Disponível em http://www.itlresearch.com/images/stories/reports/UNESCO_Brazil_Scalable_PD_and _ITL_Research_V2.pdf Acesso em 05 ago. 2019.

LEE, Jaemu; KIM, Youngtae. Development of Web-based Courseware Applied ARCS Model. IMACST, 3(1) , 33-43, 2012.

MARTÍNEZ, Azucena del Carmen. El diseño instruccional en la educación a distancia. Un acercamiento a los Modelos. Apertura, 9(10) 104-119, 2009. Disponível em http://www.redalyc.org/articulo.oa?id=68812679010 Acesso em 02 out. 2019.

MISHRA, Punya; KOEHKER, Matthew. Technological pedagogical content knowledge: a framework for teacher knowledge. Teachers college record. Volume 108, Número 6, 2006.

NOVEMBER, Alan. Empowering students with technology. Thousand Oak, CA: Corwin Press, 2010.

O’DWYER, Laura; BERNAUER, James. Quantitative research for qualitative research, London, Sage Publications, 2014.

PROJECT TOMORROW. (2010). Creating our future. Speak Up 2009 national findings. 2010. Disponível em http://www.tomorrow.org/speakup/speakup reports.html. 15.04.2013. Acesso em 26 set. 2019.

PUENTEDURA, Ruben. The SAMR model: background and exemplars. 2012. Disponível em http://www.hippasus.com/rrpweblog/archives/2012/08/23/SAMR BackgroundExemplars.pdf Acesso em 12 dez. 2019. 
PUENTEDURA, Ruben. A matrix model for designing and assessing network-enhanced courses. III Conferencia Anual MERLOT, Vancouver Canadá. 2003. Online. Disponível em http://conference.merlot.org/2003/presentations/MIC03 Puentedura matrix.pdf Acesso em 11 dez. 2019.

ROBIN, Bernard; MCNEIL, Sara. What Educators Should Know about Teaching Digital Storytelling. Digital Education Review, 22, 37-51, 2012.

SALMON, Gilly. E-Moderating: The Key to Teaching and Learning Online. Kogan Page: London, 2000.

SCHMIDT, Denise; BARAN, Evrim; THOMPSON, Ann; MISHRA, Punya; KOEHLER, Matthew; SHIN, Tae. Technological pedagogical content knowledge (TPACK): the development and validation of an assessment instrument for preservice teachers. Journal of research on technology in education. 42(2), 123-149, 2009.

SCHMIDT, Denise; BARAN, Evrim; THOMPSON, Ann; SEYMOUR, Jenna. Developing effective technological pedagogical and content knowledge (TPACK) in pre-teachers. In k. McFerrin, R. Weber, R. Carlsen D. A. Willis (eds.), Proceedings of the society for information technology \& teacher education international conference 2008 (pp. 5313-5317). Chesapeake: AACE, 2008.

SHULMAN, Lee. Those who understand: knowledge growth in teaching. Educational Researcher, 15(2), 4-14, 1986.

TALBERT, Robert. Inverted classroom. Colleagues, 9(1), Article 7. 2012. Disponível em http://scholarworks.gvsu.edu/colleagues/vol9/iss1/7 Acesso em 07 set. 2019.

TEKINER, Aylin; SHUFORD, Linda. From Distance Education to Communities of Inquiry. Em D. R. Garrison \& Z. Akyol (Eds.), Educational Communities of Inquiry Theoretical Framework, Research and Practice. Hershey, PA: IGI Global. 2013.

VYGOTSKY, Lev. Mind in society: The development of higher mental process. Cambridge, MA: Harvard University Press, 1978.

WENGLINSKI, Harold. Using technology wisely: The keys to success in schools. New York: Teachers College Press. 2005. 